\title{
Transplanted pluripotent stem cell-derived photoreceptor precursors elicit conventional and unusual light responses in mice with advanced retinal degeneration
}

\author{
Darin Zerti $^{1,2}$ (1) | Gerrit Hilgen ${ }^{1,3}$ | Birthe Dorgau $^{1}$ | Joseph Collin ${ }^{1}$ |

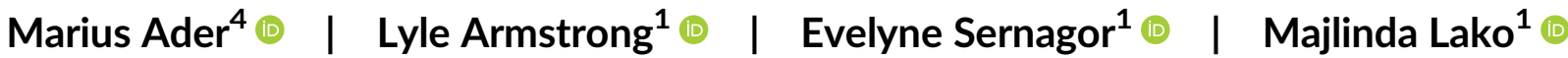

\begin{abstract}
${ }^{1}$ Biosciences Institute, Faculty of Medical Sciences, Newcastle University, Newcastle upon Tyne, UK

${ }^{2}$ Microscopy Centre and Department of Applied Clinical Sciences and Biotechnology, University of L'Aquila, L'Aquila, Italy

${ }^{3}$ Department of Applied Sciences, Northumbria University, Newcastle upon Tyne, UK

${ }^{4}$ CRTD/Center for Regenerative Therapies Dresden, Center for Molecular and Cellular Bioengineering, Technische Universität Dresden, Dresden, Germany

\section{Correspondence}

Evelyne Sernagor, PhD and Majlinda Lako, $\mathrm{PhD}$, Newcastle University, Biosciences Institute, Newcastle upon Tyne, UK.

Email: evelyne.sernagor@ncl.ac.uk (E.S.) and majlinda.lako@ncl.ac.uk (M.L.)

Funding information

Biotechnology and Biological Sciences Research Council, Grant/Award Number: BB/ P018440/1; H2020 European Research Council, Grant/Award Number: \#614620; Leverhulme Trust, Grant/Award Number: RPG2016-315; Retina UK, Grant/Award Number: \#GR593
\end{abstract}

\begin{abstract}
Retinal dystrophies often lead to blindness. Developing therapeutic interventions to restore vision is therefore of paramount importance. Here we demonstrate the ability of pluripotent stem cell-derived cone precursors to engraft and restore light responses in the Pde6brd1 mouse, an end-stage photoreceptor degeneration model. Our data show that up to $1.5 \%$ of precursors integrate into the host retina, differentiate into cones, and engraft in close apposition to the host bipolar cells. Half of the transplanted mice exhibited visual behavior and of these $33 \%$ showed binocular light sensitivity. The majority of retinal ganglion cells exhibited contrast-sensitive ON, OFF or ON-OFF light responses and even motion sensitivity; however, quite a few exhibited unusual responses (eg, light-induced suppression), presumably reflecting remodeling of the neural retina. Our data indicate that despite relatively low engraftment yield, pluripotent stem cell-derived cone precursors can elicit light responsiveness even at advanced degeneration stages. Further work is needed to improve engraftment yield and counteract retinal remodeling to achieve useful clinical applications.
\end{abstract}

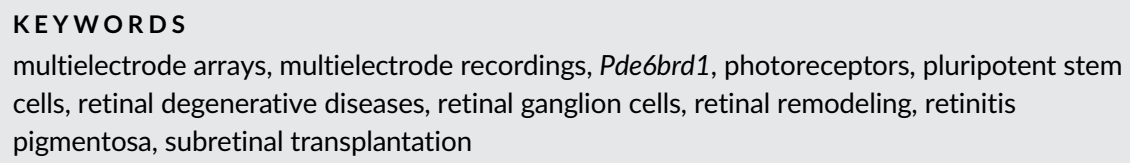

JEL CLASSIFICATION

Pluripotent Stem Cells

\section{1 | INTRODUCTION}

Genetic defects in rods, cones or in the retinal pigment epithelium trigger the loss of the sensory retina, effectively leaving the neural

Darin Zerti and Gerrit Hilgen contributed equally to this study. retina deafferented. The latter responds to this challenge by profound remodeling of the surviving cells and connectivity, ${ }^{1,2}$ posing an enormous challenge to successful potential therapies based on genetic, cellular, and bionic approaches. These changes have been extensively described in animal models such as the Pde6brd1 mouse, a model of autosomal recessive form of Retinitis Pigmentosa. ${ }^{3,4}$ 
One of the major hurdles of such remodeling is the development of ongoing $10 \mathrm{~Hz}$ oscillations in the inner retina. ${ }^{5,6}$ Arising from crossjunctional interactions between All amacrine/ON cone bipolar cells ${ }^{7,8}$ these oscillations cause very poor signal-to-noise ratio, obscuring potential retinal ganglion cell (RGC) responses to light. Gap junction blockade can circumvent that problem by dampening the oscillations, thereby significantly improving the likelihood to detect light-driven responses in RGCs. ${ }^{9-11}$

Replacement of lost photoreceptors by transplantation offers promising prospects for the reversal of end-stage degeneration. ${ }^{12}$ However, in order to be successful, the engrafted cells must establish synaptic contacts with surviving cells in the host retina, eventually leading to de novo light responses in bipolar cells and RGCs.

Since the introduction of human embryonic stem cells (hESCs) ${ }^{13}$ and induced pluripotent stem cells (hiPSCs), ${ }^{14}$ several approaches have explored the generation of retinal cells in vitro. Seminal work from the Sasai lab demonstrated the feasibility of generating murine $3 \mathrm{D}$ retinal organoids that closely follow in vivo retinogenesis ${ }^{15}$; the same group subsequently provided a protocol for the generation of human 3D retinal tissue from hESCs with a typical laminated retinal structure, harboring high numbers of photoreceptors and all other key retinal cell types. ${ }^{16}$ Since then, several groups have optimized differentiation techniques ${ }^{17-25}$ and shown that these in vitro derived retinal organoids respond to light. ${ }^{26}$ Because of their unlimited ability to proliferate and the intrinsic ability to generate light responsive laminated retinal organoids, both hESCs and hiPSCs represent the most attractive cell source to date for generating transplantable photoreceptors.

To date, several animal studies have evaluated the transplantation of photoreceptor precursors derived from human or mouse iPSCs and ESCs, with a few reporting improvements in visual function. $^{27-30}$ These studies have shown photoreceptor integration into the outer nuclear layer (ONL), the development of typical photoreceptor morphology, including outer and inner segments, and the ability to establish synaptic contacts. Until recently, it had been assumed that the reported improvements in visual function reflect donor cell integration. However, with the recent and unexpected identification of cytoplasmic material exchange from donor to host photoreceptors, most of these initial assumptions need to be revisited, especially in animal models where the host photoreceptors survive to some extent. ${ }^{31-33}$

We have reported the successful generation of a reporter labeled hESC line, in which expression of the green fluorescent protein (GFP) is controlled by CRX, a key transcription factor in retinal development with predominant expression in postmitotic photoreceptor precursors. ${ }^{34}$ These photoreceptor precursors successfully engraft in the putative ONL in the Pde6brd1 retina without cellular transfer between donor and host photoreceptors. ${ }^{35}$ Here, we demonstrate the ability of transplanted photoreceptors to successfully restore light-responses in RGCs in Pde6brd1 retinas with end-stage degeneration.

\section{Significance statement}

Replacement of the lost photoreceptors by transplantation offers promising prospects for the reversal of end-stage retinal degeneration. Published studies to date have focused on cell engraftment and cytoplasmic material exchange from donor to host photoreceptors. In the present study, the authors have advanced the field by assessing the full range of light responses that develop following transplantation of pluripotent stem cell-derived cone photoreceptors in a mouse model of advanced photoreceptor dystrophy. The authors' data show that despite a relatively low engraftment yield, cone precursors engraft, resulting in conventional light responses in ganglion cells even at advanced degeneration stages.

\section{$2 \mid$ RESULTS}

\subsection{Recovery of basic visual function upon transplantation of $\mathrm{CRX}^{+}$human photoreceptors in mice with end-stage retinal degeneration}

Photoreceptors are terminally differentiated sensory cells, which once lost, cannot regenerate. In earlier studies, we have shown that hESCderived $\mathrm{CRX}^{+}$photoreceptor precursors have the ability to engraft into Pde6brd1 mice, mature into cones ${ }^{35}$ and establish contacts with rod bipolar axon terminals. In this study, we assessed whether these transplanted photoreceptors can restore to some extent visual function. At day 90 of differentiation, retinal organoids were collected and dissociated to single cells. CRX-GFP ${ }^{+}$cells were isolated by fluorescence-activated cell sorting and transplanted bilaterally into the subretinal space of 30 immunosuppressed 10-12 weeks old Pde6brd1 mice as described previously. ${ }^{35}$ Six additional animals were injected with the vehicle solution (HBSS) (sham group). All injected eyes were examined 3-4 weeks after grafting. GFP ${ }^{+}$cells were found next to the host inner nuclear layer (INL) $(815 \pm 298$ cells per retina, Figure $1 \mathrm{~A})$ and these were localized mainly around the injection site (Figure 1B). We confirmed the photoreceptor identify of human donor cells by coexpression of GFP with the pan-photoreceptor marker Recoverin in transplanted retina wholemounts (Figure $1 \mathrm{C}, \mathrm{C}^{\prime}, \mathrm{D}, \mathrm{D}^{\prime}, \mathrm{E}, \mathrm{E}^{\prime}$ ). No $\mathrm{GFP}^{+}$ cells were detected in the sham treated group (data not shown).

In the mammalian retina, bipolar cells receive signals from photoreceptors and send integrated signals to RGCs. Photoreceptor cell axon terminals form synapses with bipolar cell dendrites and horizontal cell processes in the outer plexiform layer (OPL), and bipolar cell axon terminals connect with amacrine cell and ganglion cell dendrites in the inner plexiform layer (IPL). To investigate potential synapse formation between the donor and host, we stained the transplanted retinas with a G-protein subunit $\mathrm{GO} \alpha$ antibody, a marker for rod and 
(A)

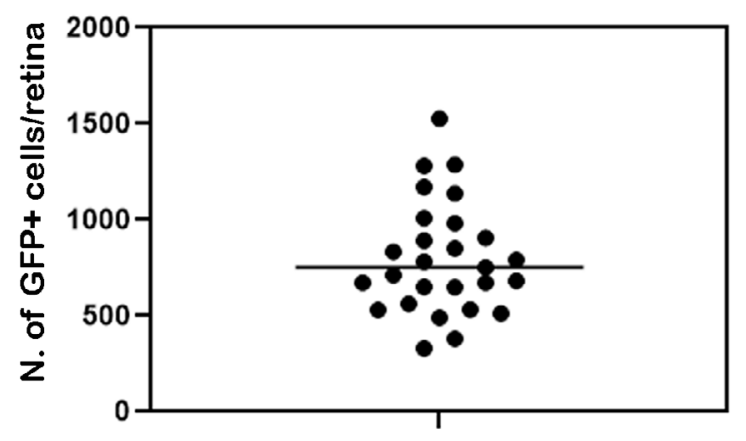

(B)

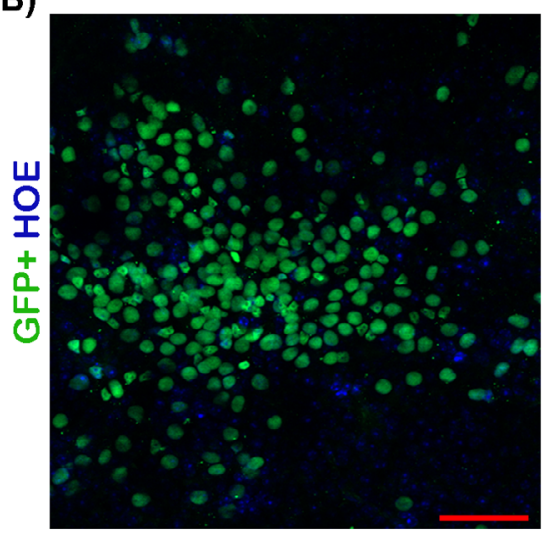

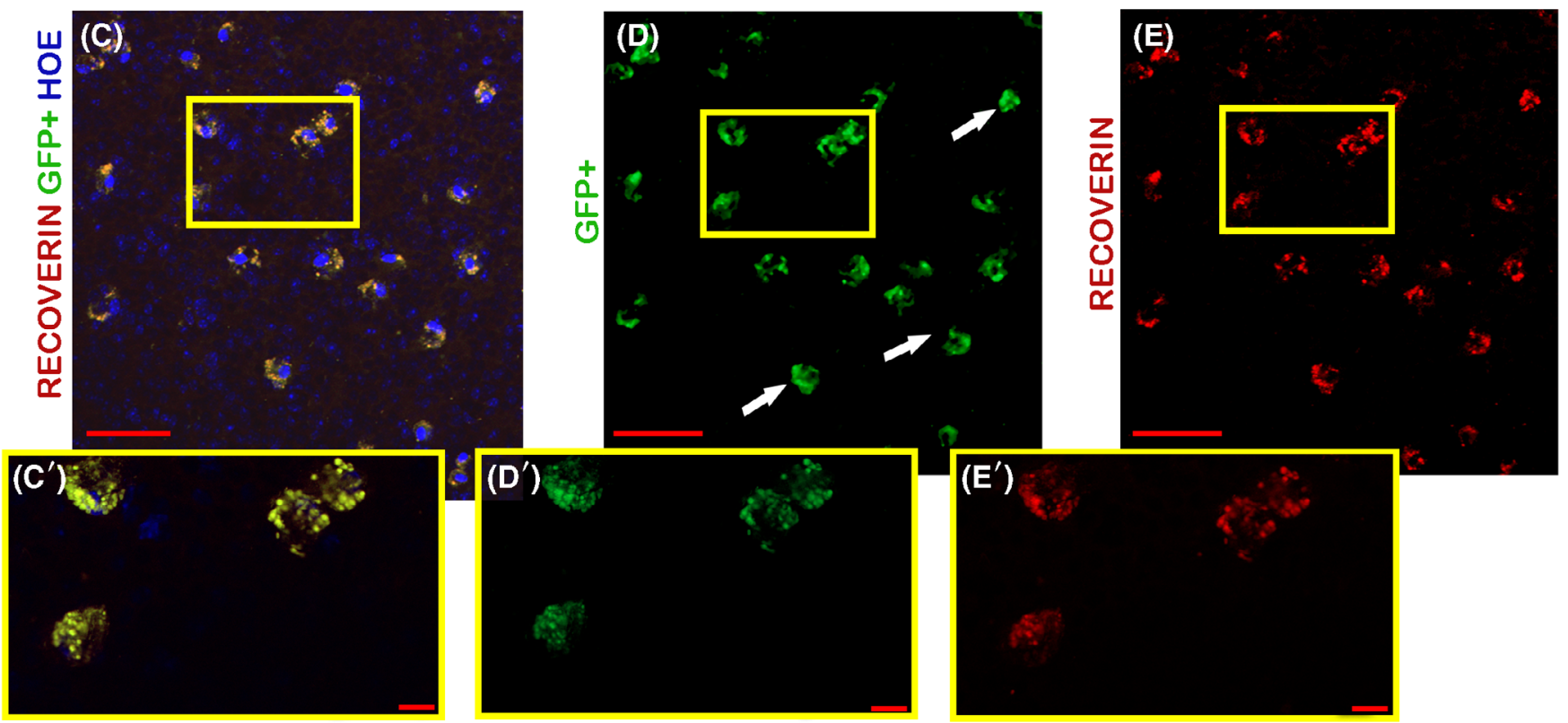

FIGURE 1 Engraftment of CRX-GFP+ cells into Pde6brd1 retinas. A, Scatter plot showing the number of GFP ${ }^{+}$cells per retina per mouse. Data are presented as number of $\mathrm{GFP}^{+}$cells \pm STD; ( $\mathrm{N}=27$ retinas); $\mathrm{B}$, Whole mount view of $\mathrm{GFP}^{+}$cells in Pde6brd1 mice retinas transplanted with $\mathrm{CRX}^{+}$cells; $\mathrm{C}-\mathrm{C}^{\prime}$, Immunohistochemical analysis for Recoverin expression in the transplanted retinas; $\mathrm{D}$-E, Individual channels of transplanted ( $D-D^{\prime}$ in green) Recoverin ${ }^{+}$(E-E' in red) cells. Scale bars, $50 \mu \mathrm{m}(B, C, D, E)$ and $10 \mu \mathrm{m}\left(C^{\prime}, D^{\prime}, E^{\prime}\right)$. GFP in (B-D) represents endogenous GFP expression. GFP, green fluorescent protein, Hoe, Hoechst

cone ON bipolar cells dendrites. ${ }^{36-38} \mathrm{GO} \alpha$ expression indicated proximity between the $\mathrm{GFP}^{+}$human photoreceptor precursors differentiated to $\mathrm{M} / \mathrm{L}$ cones (characterized by OPN1LM/MW expression) and host bipolar cells in retinal wholemounts (Figure $2 \mathrm{~A}, \mathrm{~A}^{\prime}, \mathrm{A}^{\prime \prime}$ ). We also assessed $\mathrm{GO} \alpha$ expression in cross sections, which revealed intense expression associated with $\mathrm{ON}$ bipolar dendrites that appeared to contact $\mathrm{GFP}^{+} / \mathrm{OPN} 1 \mathrm{LW}-\mathrm{MW}$ cells in the INL (Figure $2 \mathrm{~B}, \mathrm{~B}^{\prime}, \mathrm{B}^{\prime \prime}$, arrows).

To assess transplanted cell maturation and functional integration into host circuitry, we investigated restoration of visual function using two well-established visual behavioral tests, the light avoidance (Figure $3 \mathrm{~A}$ ) and the optomotor response test (Figure 3B). As mice are nocturnal animals, they naturally tend to avoid bright environments, ${ }^{39}$ a useful measure of visual function. This behavior was assessed by comparing time spent in the dark compartment (black) when the front half was illuminated (Figure $3 \mathrm{~A}$ ). Behavioral testing was conducted after overnight dark adaptation using a white light source $(\sim 1300$ lx) in the illuminated half of the testing arena. Fifty percent of the transplanted mice $(n=15)$ responded positively (Movie S1) and spent at least 5 out of 10 minutes (the total test duration) in the dark, with an average of $71.18 \% \pm 14.21$ (STD) of the test duration in the dark compartment (Figure 3C). The rest of transplanted mice that spent less than $50 \%$ of time in the dark compartment (17.68\% \pm 16.1 (STD), Figure $\mathrm{S} 1$ ) were considered as nonresponders. On the contrary, the majority of sham treated $(n=6)$ and control mice $(n=7)$ spent more time in the bright area (Figure $3 \mathrm{C}$ ), reflecting the spontaneous exploratory behavior of rodents in response to a novel environment ${ }^{40}$ (Movie S2). We also wanted to assess whether there was a correlation between the light avoidance test performance and the number of engrafted cells. Using data from seven of the transplanted mice that 

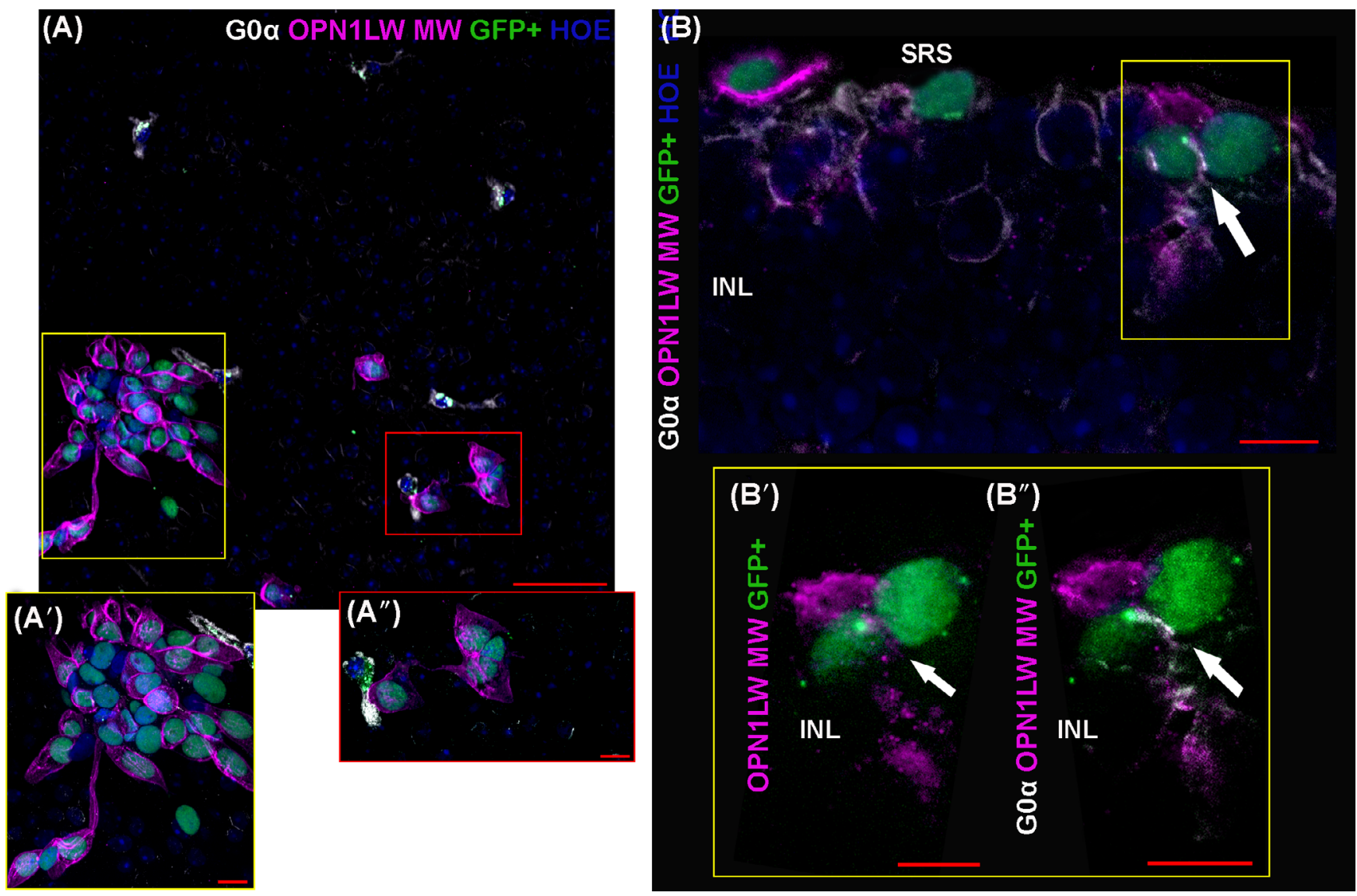

FIGURE 2 The transplanted $\mathrm{CRX}^{+}$cells are found in close contact with the host bipolar cells. A, Immunohistochemical analysis for G0 $\alpha$ in white, opsin red/green (OPN1LW/MW) in pink and GFP ${ }^{+}$cells in whole mount retinas of Pde6brd1 mice transplanted with CRX ${ }^{+}$cells. $\mathrm{A}^{\prime}-\mathrm{A}^{\prime \prime}$, Inset: high magnification images showing the GFP ${ }^{+}$-OPN1LW/MW expressing human donor cells found in close juxtaposition with the host cone bipolar cells. B, The GFP ${ }^{+}$and OPN1LW/MW immunostained cells were found in close apposition with the G0 $\alpha$ host cells in the INL. Inset: $\mathrm{B}^{\prime}$, high magnification images showing the anatomical interaction between the opsin red/green cells and the host cone bipolar cells (white arrows);

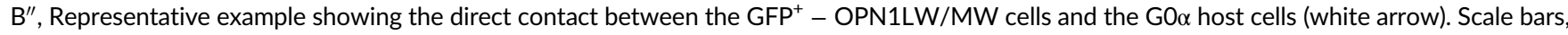
$50 \mu \mathrm{m}(A, B) ; 10 \mu \mathrm{m}\left(A^{\prime}, A^{\prime \prime}, B^{\prime}\right.$ and $\left.B^{\prime \prime}\right)$. GFP in $\left(A, A^{\prime}, A^{\prime \prime}, B\right.$ and $\left.B^{\prime \prime}\right)$ represents endogenous GFP expression. GFP, green fluorescent protein; INL, inner nuclear layer; SRS, subretinal space; Hoe, Hoechst

spent more than $50 \%$ of their time in the dark compartment, we found no correlation between the two parameters $(R=0.4130)$ (Figure 3D). This lack of correlation could be explained by the low number of engrafted cells or by the inability of several transplanted cells to form functional connections within the host retina.

Animals that exhibited light avoidance behavior, were tested for the optokinetic head tracking response to a rotating grating to find out whether they were able to discriminate motion and visual contrasts under photopic conditions (Figure 3B). Tracking in each direction is independently driven by one eye (clockwise and anticlockwise by the left and by the right eye respectively). ${ }^{29,41}$ Since mice were transplanted bilaterally, responses to leftward vs rightward moving gratings can give us useful information about functionality in each eye and the software randomly decided the direction of the grating rotation. Transplanted mice that spent more than $50 \%$ of their time in the dark compartment during the light avoidance test exhibited significantly more head tracking $(56.0 \% \pm 18.1(\mathrm{STD}), \mathrm{n}=15)$ than sham treated animals $(n=6)$ and control mice $(n=7)$, the latter two performing head tracking in less than 20\% of the trials (Figure 3D). Low head-tracking behavior in sham treated and control animals is attributed to spontaneous, involuntary head movements.

\subsection{Light sensitivity is partially restored in $\mathrm{CRX}^{+}$ transplanted retinas}

The mice that tested positive in the light-avoidance behavioral test were dark-adapted overnight and prepared for high-density largescale multielectrode array (MEA) retinal recordings the next day. Rewiring of the neural retina in photoreceptor dystrophies results in permanent RGC oscillatory activity that masks light responses because of the poor signal-to-noise ratio. An example MEA raw datatrace of such spontaneous oscillations and bursts $(5 \mathrm{~Hz}$ high-pass filtering) is illustrated in in Figure 4A (upper left trace). The underlying spurious spikes are still visible at $50 \mathrm{~Hz}$ high-pass filtering when the slow oscillations are filtered out, masking potential light-driven 
(A)

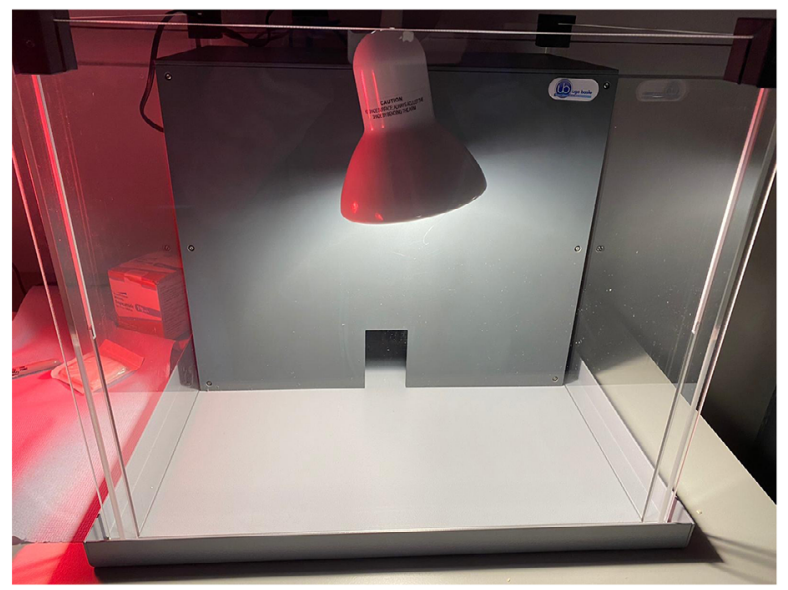

(B)

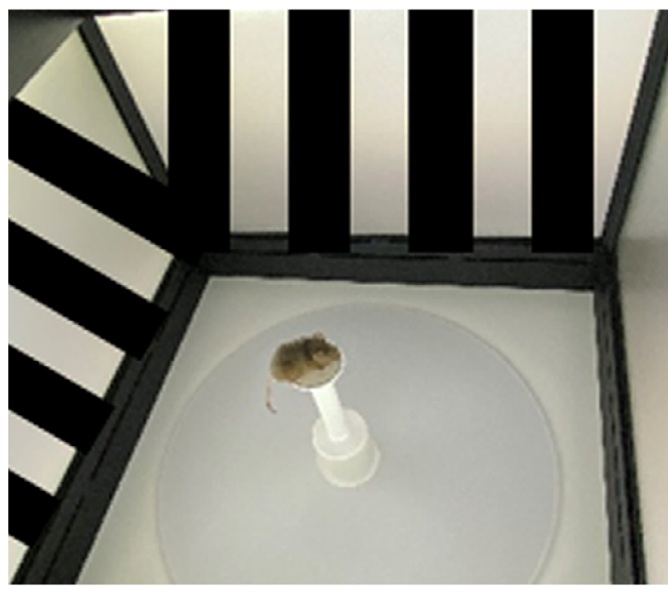

(C)

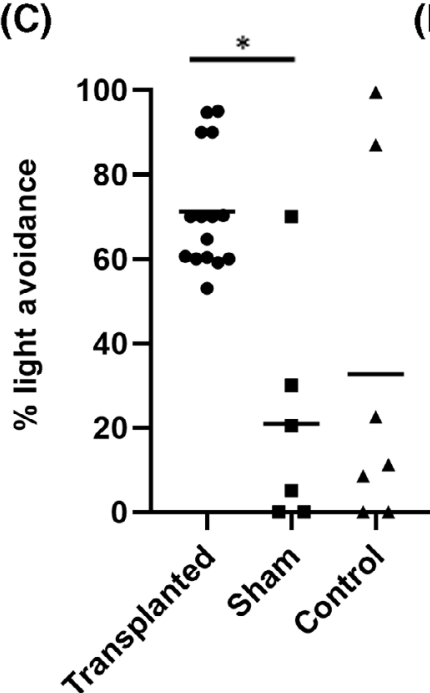

(D)

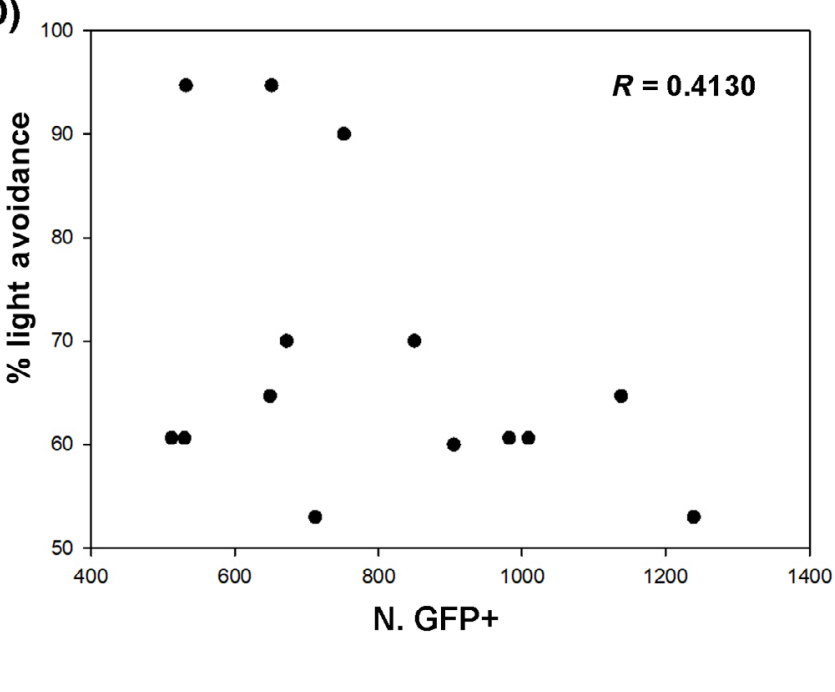

(E)

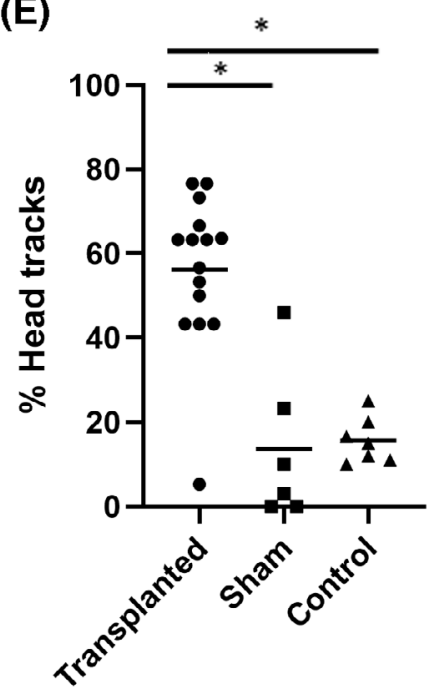

FIGURE 3 Light avoidance and Optomotor response. A, Setup for the light avoidance test; B, Photograph of the optomotor response test area; C, Scatter plot showing the results of light avoidance test in the transplanted mice that spent $>50 \%$ of time in the dark compartment $(n=15)$, the sham treated group $(n=6)$ and the control group $(n=7) ; D$, Scatter plot showing the correlation between the number of GFP engrafted cells and the light avoidance response. Data from 14 eyes (seven mice that spent more than 50\% of the time in the dark compartment during the light avoidance test) are shown; E, Scatter plots showing the percentage of successful head tracks observed for all trials for each mouse in the Optomotor test, with each dot representing the result from one animal. Significant differences $(P<.05)$ between the different experimental groups are indicated with an asterisk above the plot. For the transplanted mice, only $50 \%(n=15)$ that spent $>50 \%$ in the light avoidance test are included

responses (Figure 4A, bottom left trace). Adding the gap junction blocker meclofenamic acid (MFA) dampens the oscillations and reduces the incidence of these spurious spikes (Figure 4A, upper right trace), while preserving light responses (Figure 4C). ${ }^{10,11}$ Moreover, addition of $40 \mu \mathrm{M}$ MFA has no effect on the spike waveform shape, which is crucial for accurate isolation of single units (Figure $4 \mathrm{~B}$ ). To illustrate the signal-to-noise improvement with MFA, light driven activity of the RGC from Panel $4 B$ is shown without and with MFA in Panel $4 C$. The cell was exposed to 50 repetitions of the same full field stimuli series (trials on the $y$-axis) and the spike rasters and poststimulus time histograms (PSTH) for that particular unit are compared without (left) and with (right) $40 \mu \mathrm{M}$ MFA application. Before adding the drug, it is barely possible to see that this cell responds to the onset of the light (Figure 4C, left). With MFA, the baseline-firing rate significantly drops, which vastly improves the signal-to-noise ratio, revealing clear $\mathrm{ON}$ responses (Figure $4 \mathrm{C}$, right).

We screened six mice (12 retinas) for clear visible light responses (with $40 \mu \mathrm{M}$ MFA) to full field stimuli with increasing contrasts and square wave gratings with different bar widths and directions. We identified seven retinas (from five different mice) with RGCs showing clear responses to light (full field flashes, motion, or both). To visualize the spatial location of these light-responsive RGCs with respect to the recording area, we plotted the $\mathrm{x}, \mathrm{y}$ coordinates of all active units on the MEA in four representative explanted retinas (Figure 4D). The red dots represent the light-responding units, showing that these responsive cells always cluster in a restricted area (presumably corresponding to the injection site in the temporal retina). The gray dots show all the other RGCs with residual spontaneous activity but no light responses. 
(A)

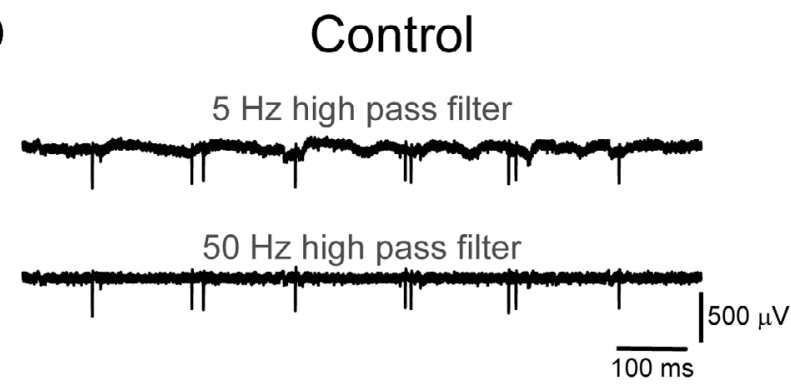

(B)

(C)
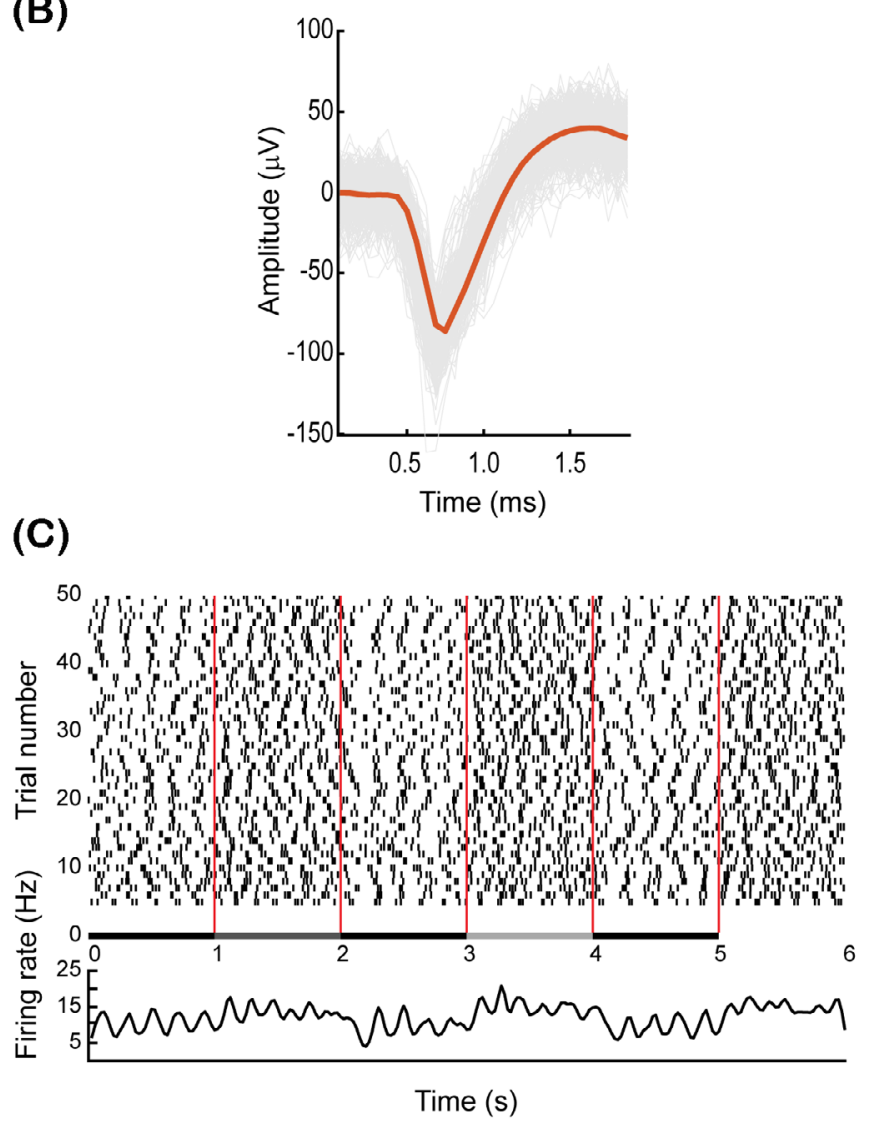

(D)
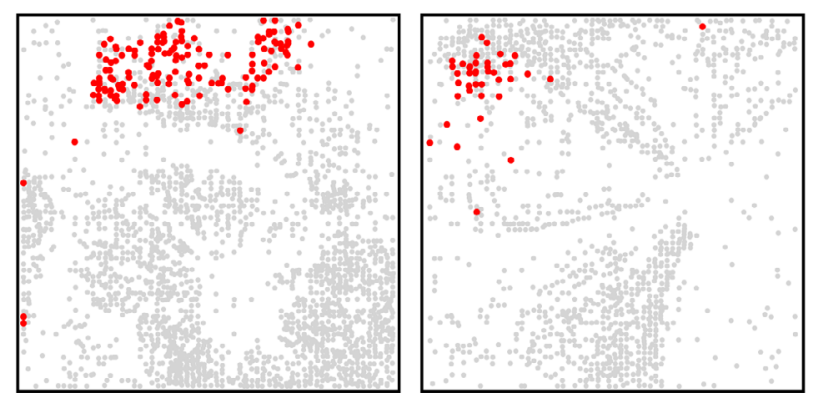

MFA $40 \mu \mathrm{M}$

$50 \mathrm{~Hz}$ high pass filter

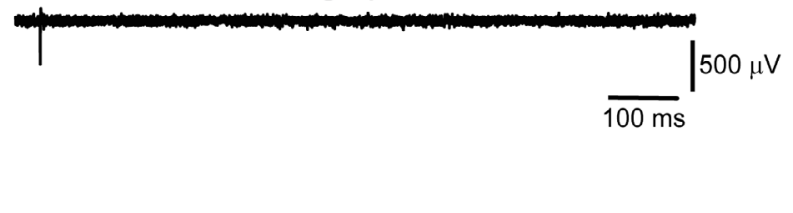

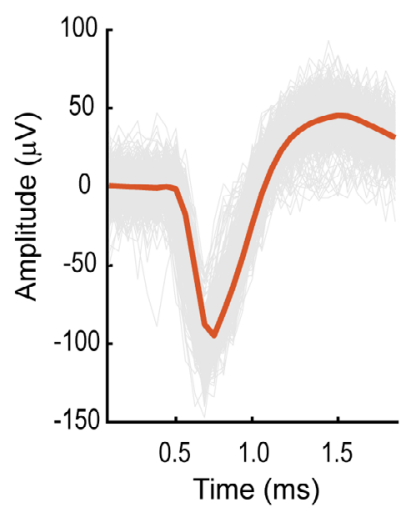

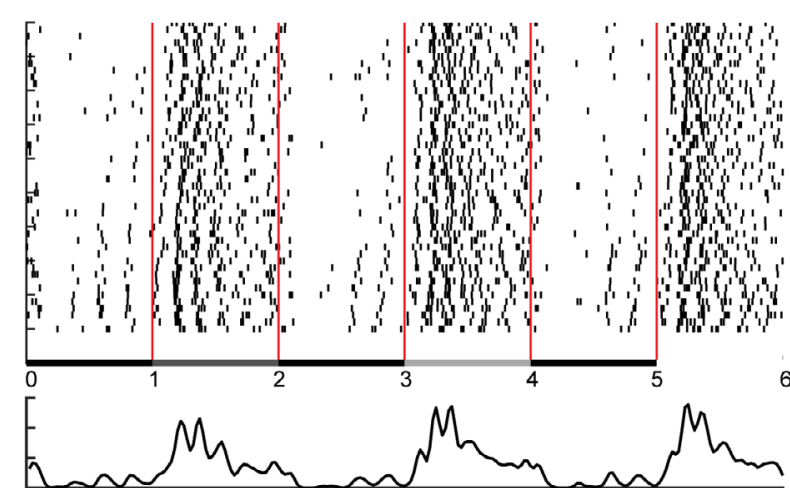

Time (s)

FIGURE 4 Dampening RGC oscillatory activity with MFA enhances the expression of light responses. A, Left: Raw data traces (from one electrode of the 4096 channels MEA) from a Pde6brd1 retina in control conditions filtered with a 5 (top) and 50 (bottom) Hz high-pass filter. Right: Raw data trace recorded ( $50 \mathrm{~Hz}$ high-pass) from a Pde6brd1 retina in $40 \mu \mathrm{M}$ meclofenamic acid (MFA). B, Extracted spike waveforms (gray plots) from one isolated RGC unit (the same unit as shown in C) in control conditions (left) and in the presence of $40 \mu \mathrm{M}$ MFA (right). The mean spike waveform is plotted in red. C, Spike raster (top) and poststimulus histograms (PSTH, bottom) for the same RGC unit in control (left) and $40 \mu$ M MFA (right). Spike raster: Spike times of 50 repetitions with the same stimulus (1-s contrast steps, indicated between spike raster and PSTH) are plotted as small vertical ticks. The average rate (spikes/s) of these repetitions is represented on the $y$-axis of the PSTH (bin size $=25 \mathrm{~ms}$ ). D, The $\mathrm{x}$ - and $\mathrm{y}$-coordinates of all spike location centers, obtained with the spike sorting package Herdingspikes2, are plotted in gray in a $64 \times 64$ grid (the electrode layout of the high density MEA). The units that were identified as light responsive are plotted in red 


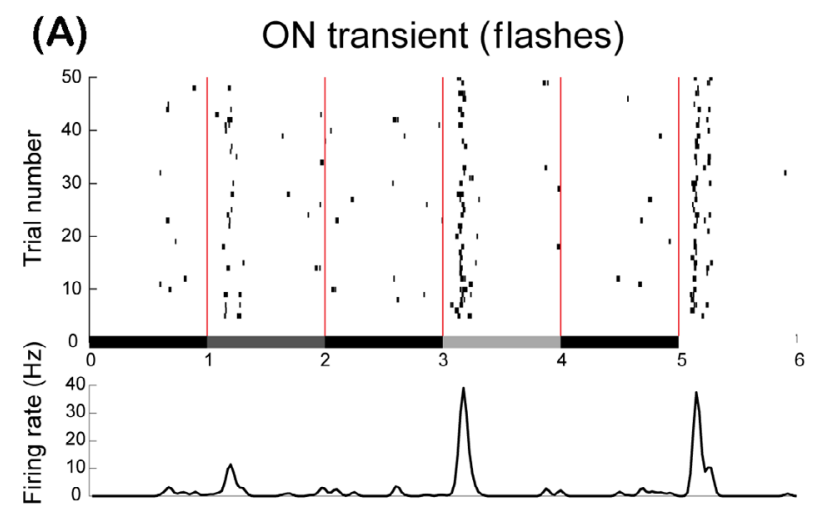

(B) ON transient (gratings)
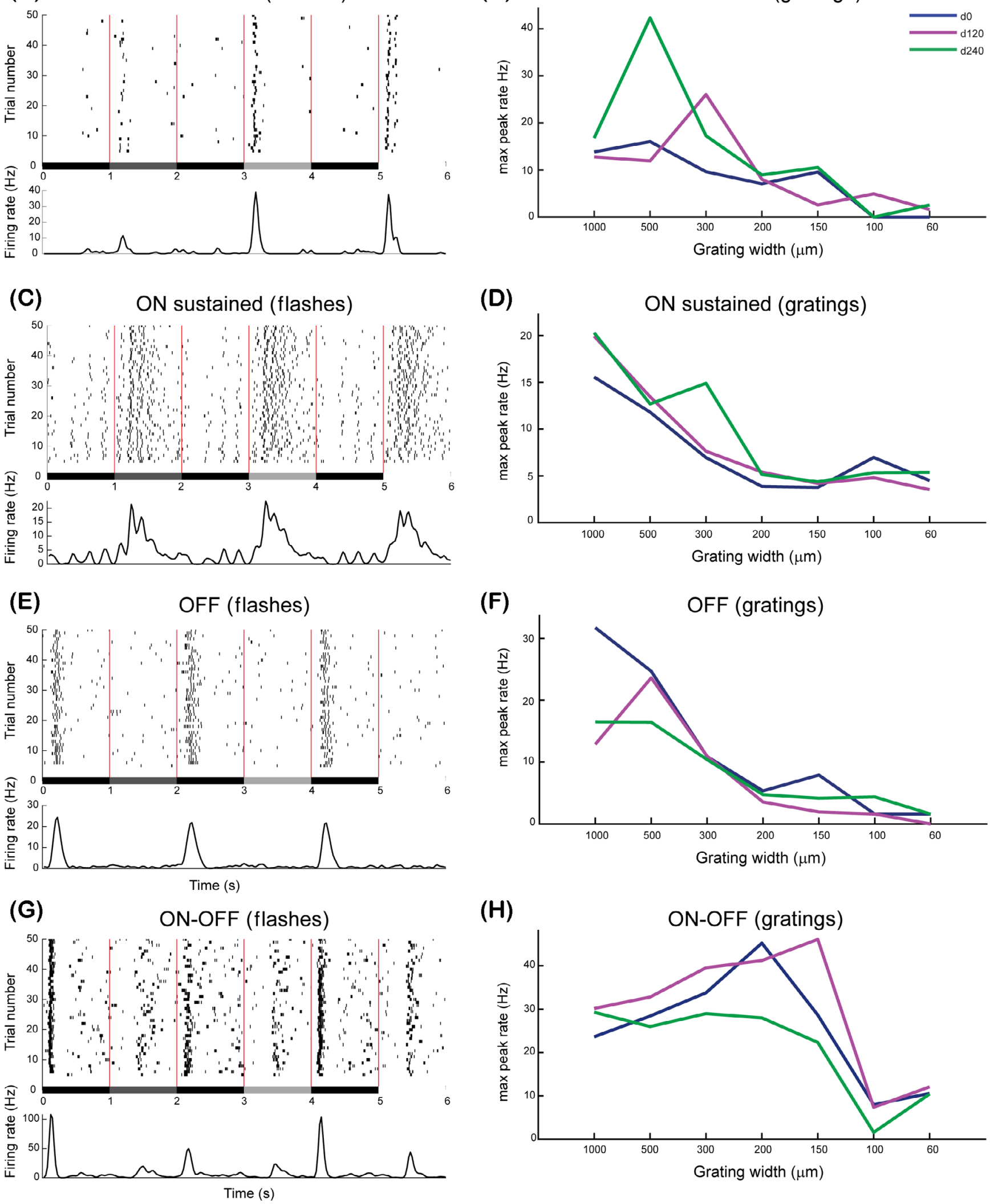

FIGURE 5 Conventional light responses. Example spike rasters and PSTHs from selected RGCs to 1-second contrast steps (flashes) of (A) ON transient, (C) ON sustained, (E) OFF and (G) ON-OFF responses in $40 \mu \mathrm{M}$ MFA. The maximum responses to square wave gratings with different bar widths ( $x$-axis) and directions ( $\mathrm{d} 0=$ blue, $\mathrm{d} 120=$ magenta, $\mathrm{d} 240=$ green) are plotted for the same units as in $A, C, E$ and $\mathrm{G}(\mathrm{B}=\mathrm{ON}$ transient, $\mathrm{D}=\mathrm{ON}$ sustained, $\mathrm{F}=\mathrm{OFF}, \mathrm{H}=\mathrm{ON}-\mathrm{OFF}$ ) 
(A) ON suppressed - OFF transient (SBL OFF trans)

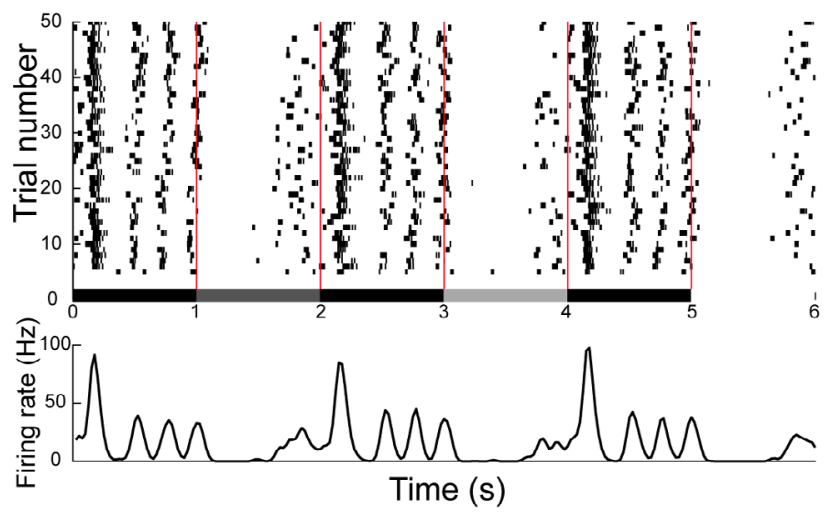

(C) ON suppressed - OFF delayed (SBL OFF delayed)

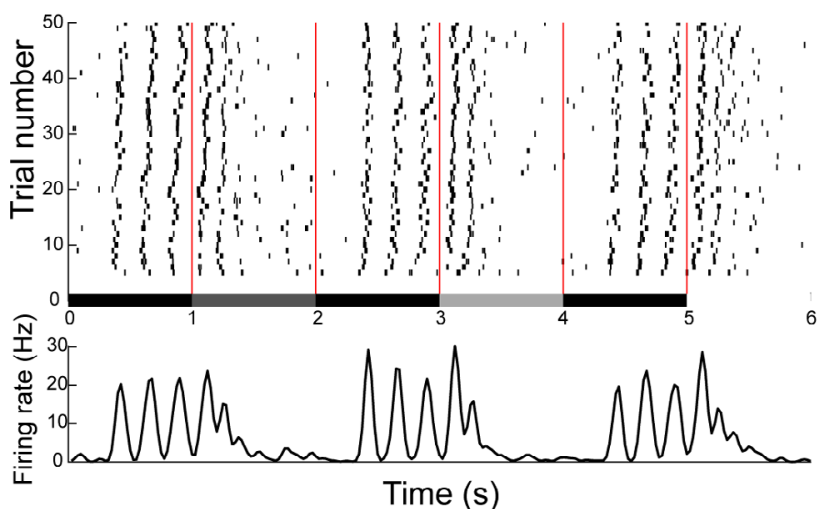

(B) ON suppressed - OFF sustained (SBL OFF sust)

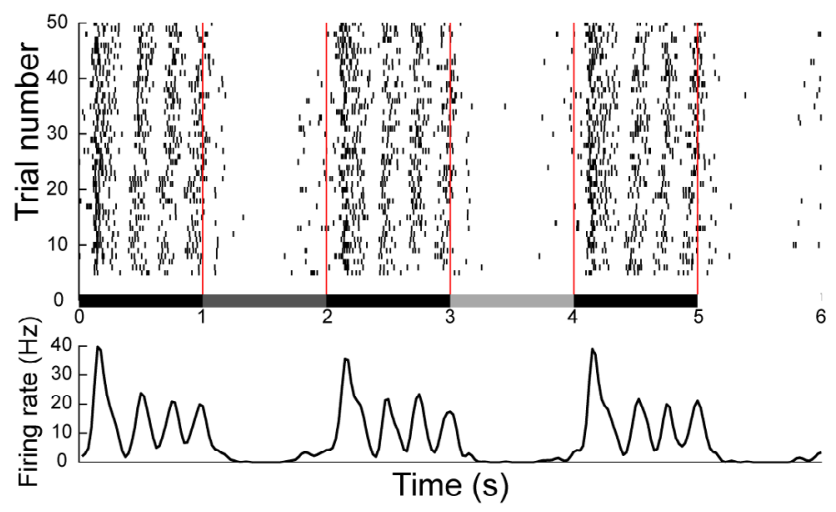

(D) OFF suppressed - ON sustained (SBD ON sust)

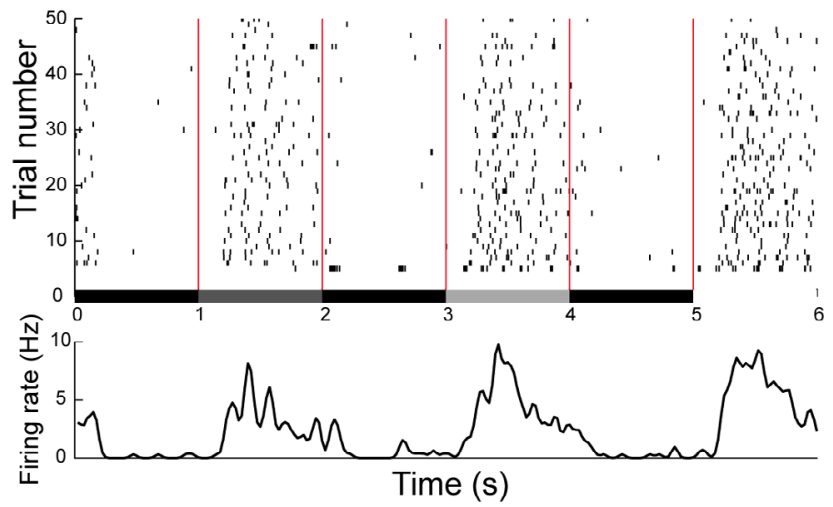

FIGURE 6 Unconventional light responses. Example spike rasters and PSTHs from selected RGCs to 1-s contrast steps (flashes) of, A, ON suppressed-OFF transient (SBL OFF trans); B, ON suppressed-OFF sustained (SBL OFF sust); C, ON suppressed-OFF delayed (SBL OFF delayed); and D, OFF suppressed-ON sustained (SBD ON sust) in $40 \mu \mathrm{M}$ MFA

The average sample size per experiment for recorded RGCs from these seven retinas was $2910 \pm 928$ (STD). On average, $45 \pm 36$ RGCs or $1.73 \pm 1.35 \%$ of the entire recorded population exhibiting neural activity also responded to light.

Overall, we observed mainly "conventional" ON, OFF and ON-OFF responses. To illustrate responses to full field flashes (Figure 5, left panels) and to different square wave gratings (Figure 5, right panels), we selected one representative cell for each of these conventional types. Many of the cells exhibited contrast sensitivity, suggesting that some of the basic retinal circuitry is preserved despite neural remodeling (eg, Figure 5A with clear increase in responsiveness for gradually brighter stimuli). Accordingly, many of these cells showed gradually increasing response suppression with an increase in the grating spatial frequency (Figure 5B,D,F) or, alternatively, had their maximum activity at a specific bar width (Figure $5 \mathrm{H}$ ). A few cells showed significantly higher activity toward a given direction (Figure $5 \mathrm{H}$, purple), but often only for a specific bar width (Figure 5B, $500 \mu \mathrm{m}$, green).

However, we also observed substantial numbers of responses that are never encountered in healthy, normal retinas (Figure 6). These unusual responses can be categorized into four main groups. Three of these groups share OFF excitatory responses and pronounced activity suppression induced at the light onset (ON suppressed or suppressed by light [SBL]). SBL OFF trans cells (Figure 6A) showed a transient and robust response to light offset, SBL OFF sust cells (Figure 6B) showed a more sustained response to light offset and SBL OFF delayed cells exhibited a delayed response to light offset (Figure 6C). The fourth group exhibited $\mathrm{ON}$ sustained responses with dark-suppressed activity (SBD ON sust, Figure 6D). We also found a few cells with faint responses to light, only visible during moving gratings, but not during static flashes (Figure 7, only motion). Control experiments with sham injected Pde6brd1 retinas did not show light responses at all. The relative incidence of the different functional groups we recorded from for all retinas is summarized in Figure 7 (details given in legend). Most of the responses were conventional (63.04\%) while the unusual response types made $22.05 \%$ and the DS/only motion types $14.91 \%$ of all light responses.

To further characterize the nature of the conventional and unusual responses, we conducted additional experiments with L-AP4, an agonist for group III metabotropic glutamate receptors and with DNQX, an antagonist for AMPA/kainate ionotropic glutamate receptors. The drugs were applied in succession, starting with $20 \mu \mathrm{M} \mathrm{L-AP4}$ to hyperpolarize ON bipolar cells, followed by $20 \mu \mathrm{M}$ L-AP4 $+20 \mu \mathrm{M}$ DNQX to additionally block AMPA/kainate ionotropic receptors in OFF bipolar cells and other retinal neurons. DNQX indeed abolished all remaining 


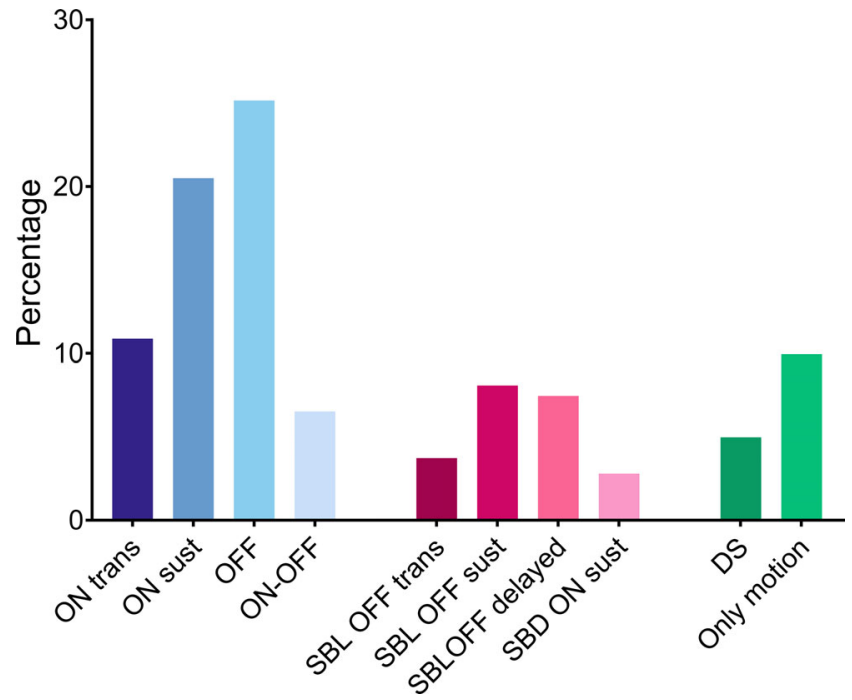

FIGURE 7 Summary of light responses grouped into four conventional response clusters (ON trans, ON sust, OFF, ON-OFF), four unconventional response types (SBL OFF trans, SBL OFF sust, SBL OFF delayed, SBD ON sust) and DS/only motion. The response types were counted from the seven light responsive retinas and values were calculated as percentage from all responding cells. In detail: ON trans (10.87\%), ON sust (20.5\%), OFF (25.16\%), ON-OFF (6.52\%) SBL OFF trans (3.73\%), SBL OFF sust (8.08\%), SBL OFF delayed (7.45\%), SBD ON sust (2.8\%), DS (4.97\%), and only motion (9.94\%)

light responses (data not shown). We compared the light responses in control conditions vs in the presence of $20 \mu \mathrm{M} \mathrm{L-AP4}$ (Figure 8). As expected, $90 \%$ of all ON transient RGC responses (see Figure $8 \mathrm{~A}$ for a representative example), were lost in the presence of L-AP4, even though there was an increase in spontaneous activity levels (Figure 8B). On the other hand, approximately $70 \%$ of all OFF responses were still present in L-AP4 (Figure 8D), but not as conspicuous as in control conditions (Figure $8 \mathrm{C}$ ). $59 \%$ of all SBL OFF transient (Figure $8 \mathrm{E}, \mathrm{F}$ ) and sustained (Figure $8 \mathrm{G}, \mathrm{H}$ ) responses behaved in a similar pattern-the initial OFF response decreased in L-AP4. Furthermore, the delayed OFF responses, which normally follow the initial OFF responses (Figure $8 \mathrm{E}$, $\mathrm{G}$ ), were less sensitive to the drug (Figure $8 \mathrm{~F}, \mathrm{H}$ ).

In summary, our data show that transplanted human photoreceptor cells are able to elicit conventional light responses from host RGCs in the majority of cases. Unconventional response types were also present at a lower incidence, which we attribute to rewiring of the inner retina that occurs during early degeneration stages, resulting in abnormal connectivity.

\section{3 | DISCUSSION}

We have developed robust protocols for generation of photoreceptors within pluripotent stem cell derived retinal organoids ${ }^{19,21,25}$ and have shown that these are able to engraft into animal models of retinal degeneration. ${ }^{35}$ Notwithstanding, there are several questions that remain to be investigated with regard to establishment of a layer of light-sensitive cells at such density that allows integration of transplanted photoreceptors within the host retinas and enables visual improvement. In this study, we investigated the ability of transplanted hESC-derived cone precursors to elicit light responses in adult RGCs in the Pde6brd1 mouse, characterized by advanced retinal degeneration. Our approach was to measure lightdriven activity from the RGC layer using high-density, large-scale MEAs that allow simultaneously recording from hundreds to thousands of RGCs over large retinal areas. Our data indicate that $80 \%$ of subretinally transplanted mice show engraftment of hESC-derived CRX-GFP ${ }^{+}$cone precursors. Up to $1.5 \%$ of cells integrated into the putative host ONL, differentiated into cones, and engrafted in close apposition with the host bipolar cells. This integration efficiency is similar to that found in wildtype or other models of cone degeneration transplanted with cone photoreceptors, as recently reported by other groups. ${ }^{42,43}$

Of the transplanted mice, $50 \%$ were able to perform the behavioral tests and $33 \%$ of the latter showed light sensitivity in both eyes, demonstrating restoration of light responses in Pde6brd1 mice. Normally, both rods and cones degenerate by the end of the first postnatal month in this mouse model of retinitis pigmentosa, resulting in complete lack of light responsiveness in all retinal neurons. Four weeks following transplantation, we were able to consistently record responses to various light stimuli, including responses to different light intensities and to motion. Rather than being scattered all over the retina, the responsive cells were always clustered in one area, presumably reflecting the single cone progenitors' injection site. We are confident that these temporally precise, stimulus-locked responses do not arise from remaining intrinsically photosensitive RGCs (ipRGCs) as the latter have very poor temporal fidelity ${ }^{44}$ in photoreceptor dystrophies. Moreover, ipRGCs are scattered all over the RGC layer, while we always saw responses only in a restricted area. In additional support, ON responses disappear in the presence of the mGluR6 agonist L-AP4 and ON and OFF responses disappear in the presence of LAP4 + DNQX (AMPA/kainate receptor antagonist), indicating that these responses are exclusively driven by glutamatergic neurotransmission, and not by ipRGCs. It is also unlikely that the responses we recorded originate from residual $\mathrm{S}$ and $\mathrm{M}$ cones reported in previous studies. ${ }^{45,46}$ Indeed, after week 12 , residual $S$ cones are restricted to the far periphery of the ventral retina, while remaining $M$ cones are located in the far periphery of the dorsal retina ${ }^{46}$; furthermore, these remaining cones are morphologically abnormal and lack inner and outer segments. ${ }^{29}$ Though our responsive RGCs cluster in spatially restricted areas, these areas always stretch from the periphery toward the center, lending support to the fact that they do not reflect surviving cones in the periphery. Finally, none of the sham-injected retinas exhibited any clear light responses.

Photoreceptor transplantation approaches to rescue visual function has made a significant leap in recent years. ${ }^{47}$ For example, Santos-Ferreira et $\mathrm{al}^{42}$ performed cone-like cell transplantation in a cone degeneration mouse model and recorded ON and OFF, and to some extent ON-OFF RGC responses in day-light conditions. Recently, Mandai et $\mathrm{al}^{48}$ transplanted mouse iPSC-derived retinal grafts in Pde6brd1 mice (7-9 weeks) and recorded simple, mainly transient ON responses to light in RGCs 2-4 months after transplantation. 
(A)

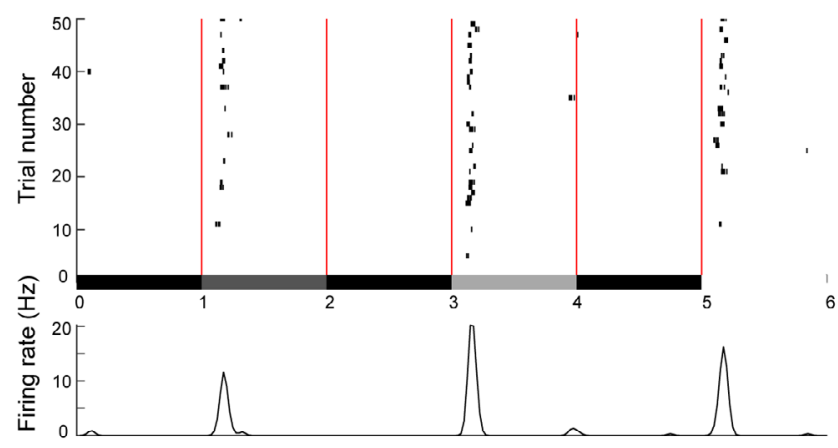

(C)

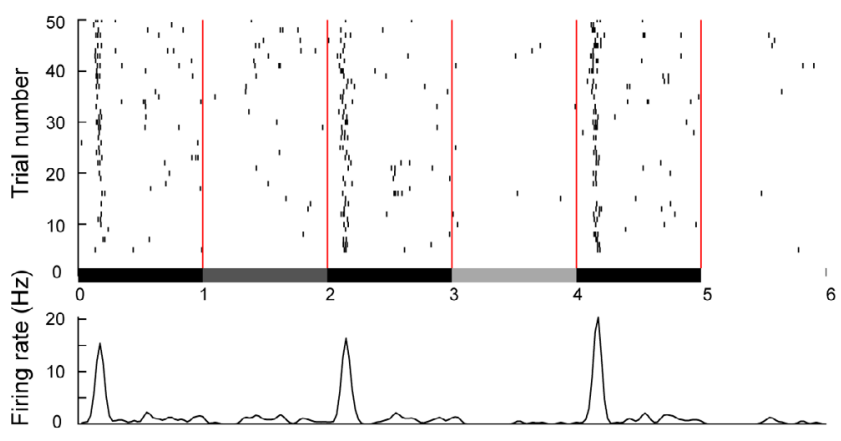

(E)

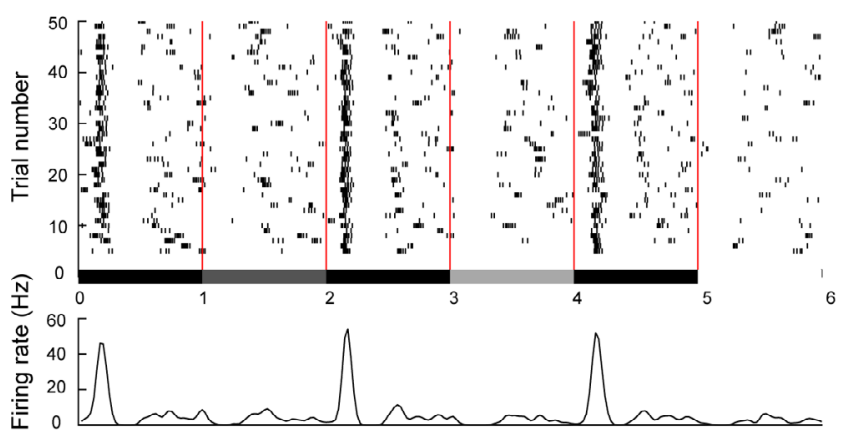

(G)

$$
\text { SBL OFF sust control }
$$

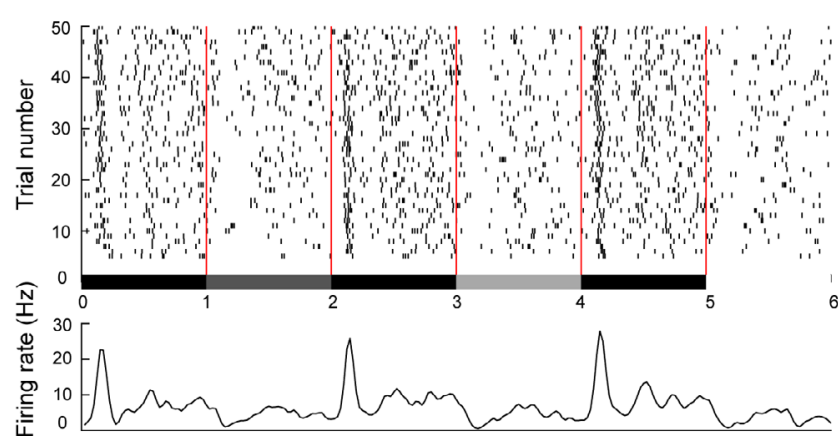

(B)

ON transient $20 \mu \mathrm{M}$ L-AP4

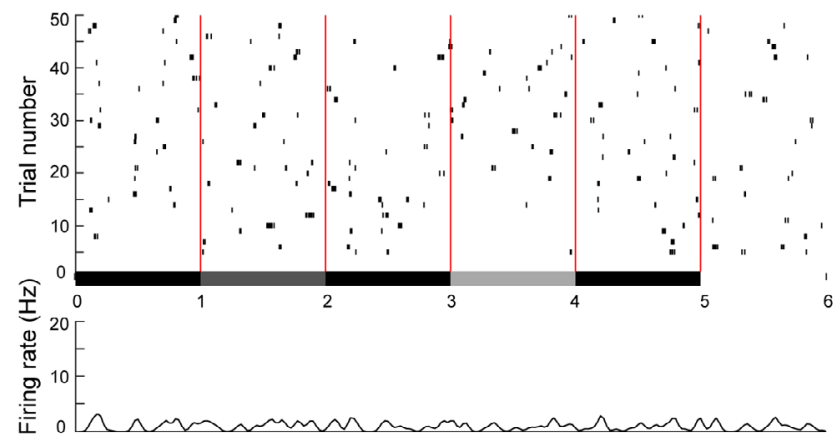

(D)

OFF $20 \mu \mathrm{M} \mathrm{L-AP4}$

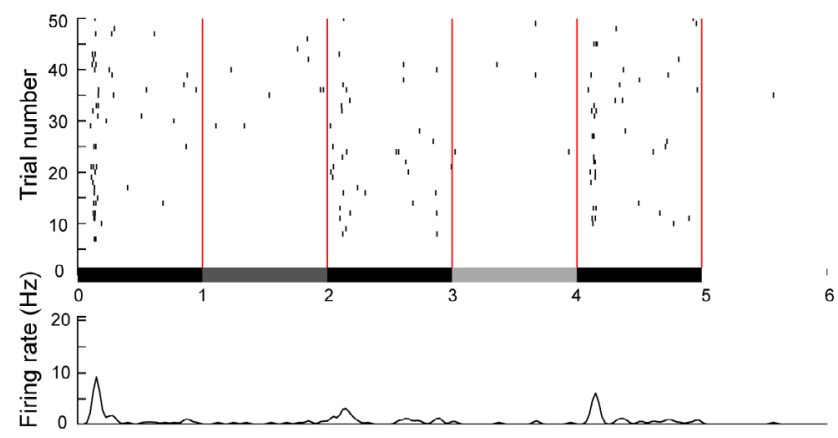

(F)

SBL OFF trans $20 \mu \mathrm{M}$ L-AP4

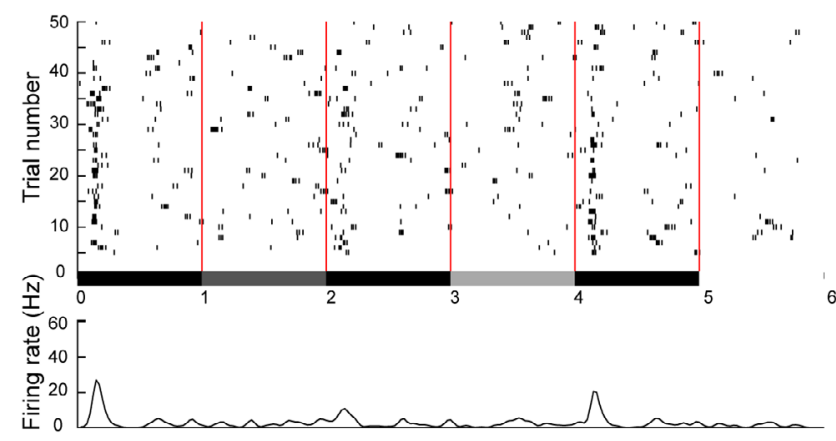

(H)

SBL OFF sust $20 \mu \mathrm{M}$ L-AP4

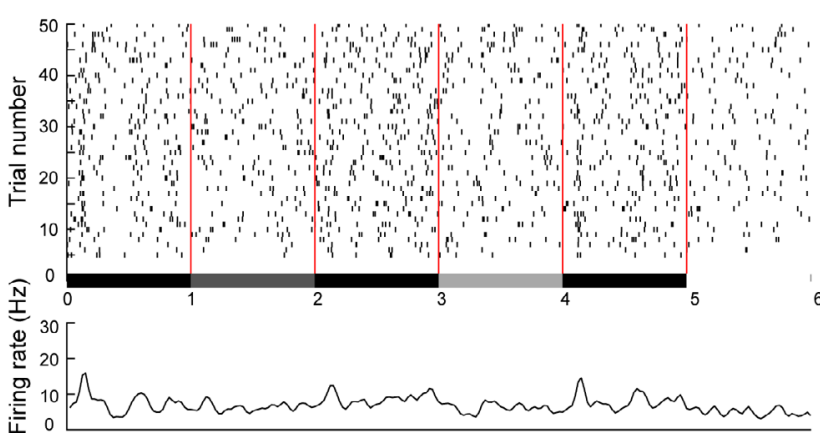

FIGURE 8 Responses in control and during activation of mGLUR6 receptors with L-AP4. Example spike rasters and PSTHs from selected RGCs to 1-s contrast steps (flashes) in control (A, C, E, G) and $20 \mu \mathrm{M} \mathrm{L-AP4} \mathrm{(B,} \mathrm{D,} \mathrm{F,} \mathrm{H).} \mathrm{A,B,} \mathrm{ON} \mathrm{transient} \mathrm{response;} \mathrm{C,D,} \mathrm{OFF} \mathrm{response;} \mathrm{E,F,}$ Suppressed by light (SBL) OFF transient response; $G, H, S B L$ OFF sustained response in $40 \mu \mathrm{M}$ MFA 
Both studies found mainly ON and OFF light responses whereas our results show a larger variety of responses including clear transient and sustained ON, OFF and ON-OFF responses shortly after transplantation. It is astonishing, but at the same time not surprising, that despite the profound morphological, biochemical, and physiological impact caused by retinal remodeling, a large set of conventional response types are still present. It is known that the surviving retinal circuitry in photoreceptor dystrophies are preserved, at least up to a certain stage of degeneration, allowing for the generation of conventional ON, OFF and ON-OFF responses following subretinal electrical stimulation (Pde6brd1 retinae $<\mathrm{P} 56^{49,50}$ ). Here, however, we report photoreceptordriven ON, OFF and ON-OFF responses in CRX+ transplanted Pde6brd1 mice older than 12 weeks, suggesting that retinal circuitry is somehow preserved for longer than previously assumed. In addition, our immunohistochemistry data suggests that GFP labeled transplanted cone precursors successfully engraft in close apposition to bipolar cells (Figure 2), which is suggestive of synaptic interactions, the latter being further corroborated by our previously published data showing Ribeye and Bassoon immunostaining in close apposition with the CRX-GFP ${ }^{+}$cells and the host inner nuclear layer. ${ }^{35}$

Importantly, we show for the first time unconventional light responses, which potentially result from novel, aberrant neural wiring that develops during remodeling of the neural retina. The ON and OFF pathways are differently affected during the progressive retinal remodeling ${ }^{6}$ and Jones et $a^{51}$ describe that some cells are less affected, showing signs of rewiring and de novo synapse formation. This suggests a certain degree of plasticity, and it is likely that transplanted cones induce the formation of functional contacts with host neurons, for example bipolar cells, or perhaps even contact RGC dendrites directly, which could explain the strong inhibitory responses to light we have observed in a substantial number of cells. For example, the unconventional SBL OFF RGC responses are characterized by complete firing blockade, often delayed, when glutamate release is decreased because of phototransduction. Given that the OFF bipolar cells relay light signals to RGCs and explain the conventional responses, we speculate that direct, de novo synaptic contacts that are established between cones and RGCs might explain these sluggish SBL OFF responses. In support of this, we found endogenous GPF fluorescence in the RGC layer of transplanted mice (Figure S2), although further experimental work is needed to assess the formation of potential synaptic contacts between transplanted cones and donor RGCs. This hypothesis is supported by earlier work ${ }^{52}$ reporting that in the peripheral retinal areas in retinitis pigmentosa patients with significant photoreceptor loss, there is dramatic sprouting of rod and cone axons into the inner nuclear layer, the inner plexiform layer, and even through the ganglion cell layer to the inner limiting membrane. However, such extensive remodeling is not observed in mouse models of Retinitis Pigmentosa such as the Pde6brd1 mice used in this study. But at the same time, we transplanted human cone precursors in these mice, hence these human cones perhaps sprout in a similar manner as they do in the human retina, and such extensive sprouting could explain the origin of the highly unusual responses we observed. However, a more detailed structural analysis would be needed to confirm this hypothesis.

\section{4 | MATERIALS AND METHODS}

\subsection{Human pluripotent stem cell culture and differentiation}

The human embryonic stem cell (hESC) line harboring the GPF reporter at the $3^{\prime} U T R$ of $C R X$ locus was expanded in mTeSR1 (StemCell Technologies) at $37^{\circ} \mathrm{C}$ and $5 \% \mathrm{CO} 2$ on 6 well plates precoated with Low Growth Factor Matrigel (Corning). Differentiation to retinal organoids was performed as described in Collin et al. ${ }^{35}$ Retinal organoids were collected on day 90 , dissociated to single cells and subjected to flow activated cell sorting to enable enrichment of CRX$\mathrm{GFP}^{+}$for transplantation.

The parent $\mathrm{H} 9 \mathrm{hESC}$ line was purchased from WiCell under the agreement 06-W097, which is renewed annually to ensure compliance with regulations set on $\mathrm{hESC}$ usage for research.

\section{2 | Subretinal transplants}

\subsection{1 | Animals}

$\mathrm{C} 3 \mathrm{H} / \mathrm{HeNH}$ sd-Pde6brd1 mice without the Gpr179 mutation were kindly gifted from Professor Robin Ali's lab (UCL London). The mice were housed in the Animal facility at Newcastle University on a standard 12-hour light/dark cycle at the same light levels throughout the experimental period. Animals were kept in ventilated cages with food and water ad libitum.

\subsection{2 | Immune suppression}

To prevent immune-rejection of the transplanted human cells, daily subcutaneous injections of Cyclosporine A $(50 \mathrm{mg} / \mathrm{kg} /$ day) were administered to the recipient animals starting at 1 day before the transplantation and maintained throughout the experiment.

\subsection{3 | Surgery and transplantation}

Surgery was performed, in male and female mice aged $\sim 10-12$ weeks, under direct ophthalmoscopy through an operating microscope, as previously described. ${ }^{35} 100000 \mathrm{CRX}^{+}$cells in a volume of $1 \mu \mathrm{L}$ volume were injected in each eye.

\section{3 $\quad$ Behavioral tests}

\subsection{1 | Light avoidance tests}

A light-chamber/dark chamber apparatus (Ugo Basile, Ltd) was used to assess the preference for light or dark compartment in male and female mice that had received bilateral CRX-GFP ${ }^{+}$cell transplants 
( $n=30$ ) or bilateral sham injection $(n=6)$ and control Pde6brd1 mice that had received no cell transplants $(n=7)$. Mice were tested in a custom-made area measuring $26 \times 26 \times 26 \mathrm{~cm}$ containing equally sized dark and light chambers connected by a $4-\times 5-\mathrm{cm}$ aperture at midpoint. The mice were dark-adapted $>12$ hours before testing. Testing was conducted in a dark room, and the light chamber was lit by a custom LED array suspended above the chamber emitting white light at $1300 \mathrm{~lx}$. Both compartments had removable tops to allow thorough cleaning with $70 \%$ ethanol before each test. Both pupils were dilated with one drop of $1 \%$ atropine instilled $\sim 10$ minutes before testing. Under dim red light, each mouse was placed in the light compartment with the light turned off, ensuring minimal tail restraint, and gently placed in the middle of the chamber to be lit (front half), facing away from the connecting aperture. The experimenter was masked to treatment group. The chambers were closed, LED light was turned on, and video recording commenced. Each trial lasted 10 minutes, and all mice were test-naive (one trial per mouse). A mouse was deemed to have entered a chamber when four paws had crossed into that compartment. Mice were assayed for time spent in the lit chamber and data were calculated manually by viewing the video recording.

\subsection{2 | Optomotor response}

We measured visual contrast sensitivity of mice by observing their optomotor responses to moving sinewave gratings randomly by the OptoMotry Software. ${ }^{53}$ Mice reflexively respond to rotating vertical gratings by moving their head in the direction of grating rotation. The protocol used yields independent measures of the acuities of right and left eyes based on the unequal sensitivities of the two eyes to pattern rotation: right and left eyes are most sensitive to counter clockwise and clockwise rotations, respectively. A virtual-reality chamber is created with four 17-in. computer monitors facing into a square. As shown in Figure 3B, a virtual cylinder, covered with a vertical sinewave grating, was drawn, and projected onto the monitors using the Optomotry software on an Apple Power Macintosh computer. The animal was placed on a platform in the center of the square and a video camera, situated above the animal, provided real-time video feedback on another computer screen. From the animal perspective, the monitors appeared as large windows through which it viewed the rotating cylinder. A red crosshair in the video frame indicated the center of the cylinder rotation. Each tested mouse was placed on the platform, the lid of the box was closed, and the animal was allowed to move freely. As the mouse moved about the platform, the experimenter followed the mouse's head with a crosshair superimposed on the video image. A trial started when the experimenter cantered the virtual drum on the head; a drifting (12 deg/s) grating then appeared. When a grating perceptible to the mouse was projected on the cylinder wall and the cylinder was rotated, the mouse normally stopped body movements and began to track the grating with reflexive head movements in concert with the rotation. The experimenter judged whether the mouse made slow tracking movements to follow the drift grating. Large repositioning and grooming movements were ignored, and the trial was restarted if tracking movements were not clearly seen. All animals were habituated before the outset of testing with handling and by placing them on the platform for a few minutes at a time. The mice were generally tested for 5-20 minutes during the first few hours of their daylight cycle. Our typical procedure was to have an experimenter make a judgment on each trial about whether the animal tracked. Although this has proved highly efficient and enables thresholds to be measured quickly, it opens the possibility of experimenter bias affecting the results. To check whether this was a real problem, for one experiment we altered the system so that the experimenter could not control the stimulus direction. Drum rotation was random from trial to trial, and the experimenter had to make a forcedchoice decision between clockwise and counter-clockwise rotation. After placing the animal on the platform and closing the lid, the experimenter waited until the animal stopped moving, at which time the gray uniform background was replaced with a 0.05 cycle/degrees spatial-frequency sine wave grating (100\% contrast) under photopic condition $\left(60 \mathrm{cds} / \mathrm{m}^{2}\right)$ and moving in one direction. To assess visual acuity, gratings had a constant contrast of $100 \%$. Using a staircase paradigm, the program converges to measures of the contrast sensitivity of both eyes defined as the spatial frequency or \% contrast yielding $\geq 70 \%$ correct observer responses. ${ }^{54}$ The animal was assessed for tracking behavior for a few seconds, and then the gray stimulus was restored. This procedure was repeated until unambiguous tracking was observed. Each experimental run consisted of a random rotation clockwise and counterclockwise, divided into a minimum of 30 trials. Each animal performed a different number of trials, depending on the level of cooperation and attention span. For each mouse, the number of successful head tracks was evaluated by the experimenter and expressed as percentage of the total number of trials used for that same animal. The short testing epochs reduced the possibility of the mouse's adapting to the stimulus and established that each animal was capable of tracking when a salient stimulus was present, and the testing with a fixed spatial frequency and contrast grating enabled each mouse's optomotor response to be properly evaluated. Occasionally, during testing, sudden squeaking noises, or taps on the lid were interspersed with the grating presentations to draw the animals' attention and stop it from moving., which facilitated more reliable and rapid testing.

\subsection{3 | Histology and immunohistochemistry}

Animals were sacrificed by cervical dislocation. Eyes were quickly removed and dissected in $4 \%$ paraformaldehyde (PFA) in PBS. Eye cups were prepared and fixed for 1 hour at $4{ }^{\circ} \mathrm{C}$, incubated overnight in $30 \%$ sucrose solution, and embedded in OCT. Cryosections were cut at $20 \mu \mathrm{m}$ thick and all sections were collected onto Superfrost Plus slides and store at $-20^{\circ} \mathrm{C}$ before the staining. Retinal section or whole mount retinas were hydrated with PBS for 30 minutes and incubated with blocking solution containing $10 \%$ goat serum and $0.3 \%$ Triton-X100 for 1 hour at RT. Slides were incubated with the appropriate 
primary antibody overnight $4^{\circ} \mathrm{C}$ (Table S1). After rinsing with PBS, sections were incubated with the secondary antibody for 2 hours at RT, rinsed and counter-stained with Hoechst. Alexa Fluor 546 and 647 secondary antibodies (Invitrogen-Molecular Probes) were used at a 1:1000 dilution. Negative controls were carried out by omitting the primary antibody.

\subsubsection{Image acquisition and processing}

Retinal sections and whole mounts retina were viewed on a Zeiss Axio ImagerZ2 equipped with Apotome 2 and Zen 2012 blue software (Zeiss, Germany). Objectives lens used were EC Plan Neofluar 20x/0.5 Ph2 and EC Plan Apochromat 63x/1.4 Ph3. Series of XZ optical sections $(<1 \mu \mathrm{m}$ thick) were taken at $1.0 \mu \mathrm{m}$ steps throughout the depth of the section. Final images are presented as a maximum projection and adjusted for brightness and contrast in Adobe Photoshop CS6 (Adobe Systems).

\section{4 | Electrophysiology}

\subsection{1 | Retina preparation for electrophysiological recordings}

All experimental procedures were approved by the ethics committee at Newcastle University and carried out following the guidelines of the UK Home Office, under control of the Animals (Scientific Procedures) Act 1986. Male and female Pde6brd1 mice aged between postnatal weeks 14-18, which passed the light avoidance and optomotor tests, were used for in vitro recordings from the RGC layer. Mice were dark-adapted overnight and killed by cervical dislocation. Eyes were enucleated, and following removal of the cornea, lens, and vitreous body, they were placed in artificial cerebrospinal fluid (aCSF) containing the following (in mM): $118 \mathrm{NaCl}, 25 \mathrm{NaHCO}_{3}, 1 \mathrm{NaH} 2 \mathrm{PO}_{4}$, $3 \mathrm{KCl}, 1 \mathrm{MgCl}_{2}, 2 \mathrm{CaCl}_{2}, 10$ glucose, and 0.5 L-Glutamine, equilibrated with $95 \% \mathrm{O}_{2}$ and $5 \% \mathrm{CO}_{2}$. The dorsal orientation was marked after enucleation. The retina was isolated from the eye cup and flattened with the temporal area, the transplantation side, covering the active recording area of the MEA. Retinas were allowed to settle for at least 2 hours before recording. All procedures were performed in dim red light and the room was maintained in darkness throughout the experiment.

\subsection{2 | High-density large-scale MEA recordings}

Recordings were performed on the BioCamX platform with HD-MEA Arena chips (3Brain $\mathrm{GmbH}$, Lanquart, Switzerland), integrating 4096 square microelectrodes in a $2.67 \times 2.67 \mathrm{~mm}$ area. The platform records at a sampling rate of $\sim 18 \mathrm{kHz} /$ electrode when using the full $64 \times 64$ array and recordings were stored in an hdf5-based data format either with a 5 or $50 \mathrm{~Hz}$ high-pass filter using 3Brain's
BrainWaveX software application. Spikes were extracted from the raw traces using a quantile-based event detection. ${ }^{55}$ Single-unit spikes were sorted using Herdingspikes2 (https://github.com/mhhennig/ HS2), an automated spike sorting method for dense, large-scale recordings. $^{56}$

Light stimuli were projected as described previously. ${ }^{11} \mathrm{~A}$ full field stimulus with increasing contrasts (1-second contrast steps, max irradiance $217 \mu \mathrm{W} / \mathrm{cm}^{2}, 1$ second black, followed by 1 second $33 \%$ gray, 1 second black, 1 second $66 \%$ gray, 1 second black, and 1 second white) was used to detect potential basic light-driven ON-OFF responses. We also used a square wave grating with different bar widths (1000, 500, 300, 200, 150, 100, and $60 \mu \mathrm{M})$ presented at three different directions $\left(0,120\right.$, and $\left.240^{\circ}\right)$ to unmask responses to motion and to test whether some RGCs were sensitive to the direction of motion (direction selectivity). The light intensity used in these experiments was set to high photopic (bright day light) conditions to ensure predominant cone activation. Bath applications with $40 \mu \mathrm{M}$ MFA (Sigma Aldrich, St. Louis, Missouri), $20 \mu \mathrm{M}$ L-AP4 (Sigma Aldrich, St. Louis, Missouri) and $20 \mu \mathrm{M}$ DNQX (Tocris, Bristol, UK) were applied for 30 minutes before recording. Statistical significance and firing rate analyses were evaluated by using Prism (GraphPad, California) and MATLAB (Mathworks, Massachusetts). Briefly, poststimulus time histograms were calculated using Matlab's histogram function. Activity plots were generated by using the scatterplot function and the $x, y$ coordinates (provided by the spike sorter Herdingspikes2) of light responsive (red) and nonresponsive (gray) cells (Figure 4D).

\section{5 | Statistical analyses}

All statistical tests were performed using Prism (GraphPad). Statistical significance was tested using one-way ANOVA (with Dunnett statistical hypothesis for multiple test correction). ${ }^{*} P$-value $<.05$; ${ }^{* *} P$-value $<.01 ;{ }^{* * *} P$-value $<.001$

\section{5 | CONCLUSION}

Our study shows that hESC-derived cone precursors engraft and elicit both conventional and unconventional light responses in mice with advanced retinal degeneration, despite a relatively low number of engrafted cells. This demonstrates that hESC-derived cones provide a useful source of cells for transplantation into demised retinas; however, to progress this to human clinical trials, further work is needed to increase the number of engrafted cells and slow down remodeling of the neural retina to achieve clinically useful vision improvement in patients with degenerative retinal diseases.

\section{ACKNOWLEDGMENTS}

We are grateful to ERC (\#614620), RP Fighting Blindness (\#GR593), Leverhulme Trust (RPG-2016-315), and BBSRC (BB/P018440/1) for 
funding this work. We would also like to thank Prof Robin Ali for the kind donation of Pde6brd1 mice and Dr Kathy Murphy at the Newcastle Comparative Biology Centre for fruitful discussions on animal surgery and welfare.

\section{CONFLICT OF INTEREST}

The authors declared no potential conflicts of interest.

\section{AUTHOR CONTRIBUTIONS}

D.Z., G.H.: experimental design, performed research, data collection and analysis, figure preparation and manuscript writing, approved the final version of the manuscript; B.D., J.C., L.A.: performed research and data collection, approved the final version of the manuscript; M.A.: donated reagents, performed training in subretinal transplants and visual tests, approved the final version of the manuscript; E.S., M. L.: study and experimental design, data analysis, figure preparation, manuscript writing and fund raising, approved the final version of the manuscript.

\section{DATA AVAILABILITY STATEMENT}

The data that support the findings of this study are available from the corresponding author upon reasonable request.

\section{ETHICS STATEMENT}

All experimental work performed in this study was in accordance with the United Kingdom Animals (Scientific Procedures) Act 1986 and carried out in accordance with protocols approved by the Animal Welfare and Ethics Committee of Newcastle University. All efforts were made to minimize the number and the suffering of animals used in these experiments.

\section{ORCID}

Darin Zerti (D) https://orcid.org/0000-0003-0865-8088

Marius Ader (DD https://orcid.org/0000-0001-9467-7677

Lyle Armstrong (iD https://orcid.org/0000-0002-7234-9362

Evelyne Sernagor (D) https://orcid.org/0000-0003-3803-257X

Majlinda Lako (D) https://orcid.org/0000-0003-1327-8573

\section{REFERENCES}

1. Marc RE, Jones BW, Watt CB, Strettoi E. Neural remodeling in retinal degeneration. Prog Retin Eye Res. 2003;22:607-655.

2. Jones BW, Marc RE. Retinal remodeling during retinal degeneration. Exp Eye Res. 2005;81:123-137.

3. Carter-Dawson LD, LaVail MM, Sidman RL. Differential effect of the rd mutation on rods and cones in the mouse retina. | IOVS | ARVO Journals. 1978;17(6):489-498. https://iovs.arvojournals.org/article. aspx?articleid=2175613. Accessed September 4, 2020.

4. Farber DB, Flannery JG, Bowes-Rickman C. The rd mouse story: seventy years of research on an animal model of inherited retinal degeneration. Prog Retin Eye Res. 1994;13:31-64.

5. Menzler J, Zeck G. Network oscillations in rod-degenerated mouse retinas. J Neurosci. 2011;31:2280-2291.

6. Stasheff SF. Emergence of sustained spontaneous hyperactivity and temporary preservation of OFF responses in ganglion cells of the retinal degeneration (rd1) mouse. J Neurophysiol. 2008;99: $1408-1421$.
7. Choi $\mathrm{H}$, Zhang L, Cembrowski MS, et al. Intrinsic bursting of All amacrine cells underlies oscillations in the $\mathrm{rd} 1$ mouse retina. J. Neurophysiol. 2014;112:1491-1504.

8. Trenholm S, Borowska J, Zhang J, et al. Intrinsic oscillatory activity arising within the electrically coupled All amacrine-ON cone bipolar cell network is driven by voltage-gated $\mathrm{Na}+$ channels. J. Physiol. 2012; 590:2501-2517.

9. Toychiev AH, Ivanova E, Yee CW, Sagdullaev BT. Block of gap junctions eliminates aberrant activity and restores light responses during retinal degeneration. J Neurosci. 2013;33:13972-13977.

10. Barrett JM, Degenaar P, Sernagor E. Blockade of pathological retinal ganglion cell hyperactivity improves optogenetically evoked light responses in rd1 mice. Front Cell Neurosci. 2015;9:330-344.

11. Barrett JM, Hilgen G, Sernagor E. Dampening spontaneous activity improves the light sensitivity and spatial acuity of optogenetic retinal prosthetic responses. Sci Rep. 2016;6:33565.

12. Gonzalez-Cordero A, Kruczek K, Naeem A, et al. Recapitulation of human retinal development from human pluripotent stem cells generates transplantable populations of cone photoreceptors. Stem Cell Rep. 2017;9:820-837.

13. Thomson JA, Itskovitz-Eldor J, Shapiro SS, et al. Embryonic stem cell lines derived from human blastocysts. Science. 1998;282:1145-1147.

14. Takahashi K, Tanabe K, Ohnuki M, et al. Induction of pluripotent stem cells from adult human fibroblasts by defined factors. Cell. 2007;131: 861-872.

15. Eiraku $\mathrm{M}$, Takata $\mathrm{N}$, Ishibashi $\mathrm{H}$, et al. Self-organizing optic-cup morphogenesis in three-dimensional culture. Nature. 2011;472:51-58.

16. Nakano T, Ando S, Takata N, et al. Self-formation of optic cups and storable stratified neural retina from human ESCs. Cell Stem Cell. 2012;10:771-785.

17. Boucherie C, Sowden JC, Ali RR. Induced pluripotent stem cell technology for generating photoreceptors. Regen Med. 2011;6: 469-479.

18. Capowski EE, Samimi K, Mayerl SJ, et al. Reproducibility and staging of 3D human retinal organoids across multiple pluripotent stem cell lines. Development. 2019;146:dev171686.

19. Dorgau B, Felemban M, Hilgen G, et al. Decellularised extracellular matrix-derived peptides from neural retina and retinal pigment epithelium enhance the expression of synaptic markers and light responsiveness of human pluripotent stem cell derived retinal organoids. Biomaterials. 2019;199:63-75.

20. Gonzalez-Cordero A, West EL, Pearson RA, et al. Photoreceptor precursors derived from three-dimensional embryonic stem cell cultures integrate and mature within adult degenerate retina. Nat Biotechnol. 2013;31:741-747.

21. Mellough CB, Collin J, Khazim M, et al. IGF-1 signaling plays an important role in the formation of three-dimensional laminated neural retina and other ocular structures from human embryonic stem cells. Stem Cells. 2015;33:2416-2430.

22. Mellough CB, Collin J, Queen R, et al. Systematic comparison of retinal organoid differentiation from human pluripotent stem cells reveals stage specific, cell line, and methodological differences. Stem CelLS Translational Medicine. 2019;8:694-706.

23. Phillips MJ, Capowski EE, Petersen A, et al. Generation of a rodspecific NRL reporter line in human pluripotent stem cells. Sci Rep. 2018;8:2370.

24. Zhong X, Gutierrez C, Xue T, et al. Generation of three-dimensional retinal tissue with functional photoreceptors from human iPSCs. Nat Commun. 2014;5:4047.

25. Zerti D, Dorgau B, Felemban M, et al. Developing a simple method to enhance the generation of cone and rod photoreceptors in pluripotent stem cell-derived retinal organoids. STEM CELLS. 2020;38:45-51.

26. Hallam D, Hilgen G, Dorgau B, et al. Human-induced pluripotent stem cells generate light responsive retinal organoids with variable and nutrient-dependent efficiency. STEM CELLS. 2018;36:1535-1551. 
27. Pearson RA, Barber AC, Rizzi M, et al. Restoration of vision after transplantation of photoreceptors. Nature. 2012;485:99-103.

28. Singh MS, Issa PC, Butler R, et al. Reversal of end-stage retinal degeneration and restoration of visual function by photoreceptor transplantation. Proc Natl Acad Sci USA. 2013;110:1101-1106.

29. Barnea-Cramer AO, Wang W, Lu S-J, et al. Function of human pluripotent stem cell-derived photoreceptor progenitors in blind mice. Sci Rep. 2016;6:29784.

30. Lamba DA, Gust J, Reh TA. Transplantation of human embryonic stem cell-derived photoreceptors restores some visual function in Crxdeficient mice. Cell Stem Cell. 2009;4:73-79.

31. Santos-Ferreira T, Llonch S, Borsch O, Postel K, Haas J, Ader M. Retinal transplantation of photoreceptors results in donor-host cytoplasmic exchange. Nat Commun. 2016;7:13028.

32. Pearson RA, Gonzalez-Cordero A, West EL, et al. Donor and host photoreceptors engage in material transfer following transplantation of post-mitotic photoreceptor precursors. Nat Commun. 2016;7: 13029.

33. Nickerson PEB, Ortin-Martinez A, Wallace VA. Material exchange in photoreceptor transplantation: updating our understanding of dono$\mathrm{r} /$ host communication and the future of cell engraftment science. Front Neural Circuits. 2018;12(6):12-17.

34. Collin J, Mellough CB, Dorgau B, Przyborski S, Moreno-Gimeno I, Lako $M$. Using zinc finger nuclease technology to generate CRXreporter human embryonic stem cells as a tool to identify and study the emergence of photoreceptors precursors during pluripotent stem cell differentiation. STEM CELLS. 2016;34:311-321.

35. Collin J, Zerti D, Queen R, et al. CRX expression in pluripotent stem cell-derived photoreceptors marks a transplantable subpopulation of early cones. Stem CeLLS. 2019;37:609-622.

36. Hilgen $\mathrm{G}$, Huebner AK, Tanimoto N, et al. Lack of the sodium-driven chloride bicarbonate exchanger NCBE impairs visual function in the mouse retina. PLoS One. 2012;7:e46155.

37. Haverkamp S, Wässle H. Immunocytochemical analysis of the mouse retina. J Comp Neurol. 2000;424:1-23.

38. Vardi N. Alpha subunit of G(o) localizes in the dendritic tips of ON bipolar cells. J Comp Neurol. 1998;395:43-52.

39. Misslin R, Belzung C, Vogel E. Behavioural validation of a light/dark choice procedure for testing anti-anxiety agents. Behav Processes. 1989;18:119-132.

40. Bourin M, Hascoët M. The mouse light/dark box test. Eur J Pharmacol. 2003;463:55-65.

41. Harvey RJ, De'Sperati C, Strata P. The early phase of horizontal optokinetic responses in the pigmented rat and the effects of lesions of the visual cortex. Vision Res. 1997;37:1615-1625.

42. Santos-Ferreira T, Postel K, Stutzki H, Kurth T, Zeck G, Ader M. Daylight vision repair by cell transplantation. STEM CeLLS. 2015;33: 79-90.

43. Smiley S, Nickerson PE, Comanita L, et al. Establishment of a cone photoreceptor transplantation platform based on a novel cone-GFP reporter mouse line. Sci Rep. 2016;6:1-15.
44. Procyk CA, Eleftheriou CG, Storchi R, et al. Spatial receptive fields in the retina and dorsal lateral geniculate nucleus of mice lacking rods and cones. J Neurophysiol. 2015;114:1321-1330.

45. Narayan DS, Ao J, Wood JPM, Casson RJ, Chidlow G. Spatiotemporal characterization of S- and $\mathrm{M} / \mathrm{L}$-cone degeneration in the Rd1 mouse model of retinitis pigmentosa. BMC Neurosci. 2019;20:46.

46. Lin B, Masland RH, Strettoi E. Remodeling of cone photoreceptor cells after rod degeneration in rd mice. Exp Eye Res. 2009;88: 589-599.

47. Gasparini SJ, Llonch S, Borsch O, Ader M. Transplantation of photoreceptors into the degenerative retina: current state and future perspectives. Prog Retin Eye Res. 2019;69:1-37.

48. Mandai M, Fujii M, Hashiguchi T, et al. iPSC-derived retina transplants improve vision in rd1 end-stage retinal-degeneration mice. Stem Cell Rep. 2017;8:69-83.

49. Stutzki H, Helmhold F, Eickenscheidt M, Zeck G. Subretinal electrical stimulation reveals intact network activity in the blind mouse retina. J Neurophysiol. 2016;116:1684-1693.

50. Haq W, Dietter J, Zrenner E. Electrical activation of degenerated photoreceptors in blind mouse retina elicited network-mediated responses in different types of ganglion cells. Sci Rep. 2018;8:16998.

51. Jones BW, Watt CB, Frederick JM, et al. Retinal remodeling triggered by photoreceptor degenerations. J Comp Neurol. 2003;464:1-16.

52. Li ZY, Kljavin IJ, Milam AH. Rod photoreceptor neurite sprouting in retinitis pigmentosa. J Neurosci. 1995;15:5429-5438.

53. Prusky GT, Alam NM, Beekman S, Douglas RM. Rapid quantification of adult and developing mouse spatial vision using a virtual optomotor system. Investig Ophthalmol Vis Sci. 2004;45:4611-4616.

54. Umino Y, Solessio E, Barlow RB. Speed, spatial, and temporal tuning of rod and cone vision in mouse. J Neurosci. 2008;28:189-198.

55. Muthmann JO, Amin H, Sernagor E, et al. Spike detection for large neural populations using high density multielectrode arrays. Front Neuroinform. 2015;9:1-21.

56. Hilgen G, Sorbaro M, Pirmoradian S, et al. Unsupervised spike sorting for large-scale, high-density multielectrode arrays. Cell Rep. 2017;18: 2521-2532.

\section{SUPPORTING INFORMATION}

Additional supporting information may be found online in the Supporting Information section at the end of this article.

How to cite this article: Zerti D, Hilgen G, Dorgau B, et al. Transplanted pluripotent stem cell-derived photoreceptor precursors elicit conventional and unusual light responses in mice with advanced retinal degeneration. Stem Cells. 2021; 1-15. https://doi.org/10.1002/stem.3365 